\title{
A Hypothesis for the Intensification of Tropical Cyclones under Moderate Vertical Wind Shear
}

\author{
ROSIMAR RIOS-BERRIOS \\ Department of Atmospheric and Environmental Sciences, University at Albany, State University of New York, \\ Albany, New York, and National Center for Atmospheric Research, Boulder, Colorado \\ CHRISTOPHER A. DAVIS \\ National Center for Atmospheric Research, Boulder, Colorado \\ RYAN D. TORN \\ Department of Atmospheric and Environmental Sciences, University at Albany, State University of New York, \\ Albany, New York
}

(Manuscript received 28 February 2018, in final form 14 August 2018)

\begin{abstract}
A major open issue in tropical meteorology is how and why some tropical cyclones intensify under moderate vertical wind shear. This study tackles that issue by diagnosing physical processes of tropical cyclone intensification in a moderately sheared environment using a 20-member ensemble of idealized simulations. Consistent with previous studies, the ensemble shows that the onset of intensification largely depends on the timing of vortex tilt reduction and symmetrization of precipitation. A new contribution of this work is a process-based analysis following a shear-induced midtropospheric vortex with its associated precipitation. This analysis shows that tilt reduction and symmetrization precede intensification because those processes are associated with a substantial increase in near-surface vertical mass fluxes and equivalent potential temperature. A vorticity budget demonstrates that the increased near-surface vertical mass fluxes aid intensification via near-surface stretching of absolute vorticity and free-tropospheric tilting of horizontal vorticity. Importantly, tilt reduction happens because of a vortex merger process-not because of advective vortex alignment - that yields a single closed circulation over a deep layer. Vortex merger only happens after the midtropospheric vortex reaches upshear left, where the flow configuration favors near-surface vortex stretching, deep updrafts, and a substantial reduction of low-entropy fluxes. These results lead to the hypothesis that intensification under moderate shear happens if and when a "restructuring" process is completed, after which a closed circulation favors persistent vorticity spinup and recirculating warm, moist air parcels.
\end{abstract}

\section{Introduction}

A major impediment of accurate tropical cyclone (TC) forecasts is the interaction of TCs with environmental vertical wind shear (VWS). Although VWS is one of the most inhibiting factors of TC intensification (Merrill 1988; DeMaria and Kaplan 1994; Paterson et al. 2005; Hendricks et al. 2010), TCs can intensify under VWS magnitudes that are neither too weak nor too strong (moderate shear hereafter; Molinari et al. 2004, 2006; Molinari and Vollaro 2010; Montgomery et al. 2010;

Corresponding author: Rosimar Rios-Berrios, rberrios@ucar. edu
Foerster et al. 2014; Stevenson et al. 2014; Rios-Berrios et al. 2016b,a; Zawislak et al. 2016; Rios-Berrios and Torn 2017; Nguyen et al. 2017). Consequently, intensity changes are more difficult to predict for moderate VWS scenarios than for weak or strong VWS (Bhatia and Nolan 2013; Finocchio and Majumdar 2017). This issue represents a major forecasting challenge as recognized by a former hurricane specialist who stated that "one of [their] biggest challenges is trying to sort out what's going to happen at intermediate levels of shear" (Sumwalt et al. 2017, p. 3). Motivated by this challenge and its important implications, this study aims at identifying physical processes preceding TC intensification under moderate VWS. 
Several theories exist to explain TC intensification; however, various limitations prevent their applications to the TC-VWS problem. Most theories describe intensification as a feedback between surface fluxes, near-surface convergence of energy and angular momentum, and latent heat release (Ooyama 1964, 1969, 1982; Charney and Eliassen 1964; Emanuel 1986). Such feedback, however, is based on an axisymmetric view of mature TCs. An alternate paradigm was proposed by Van Sang et al. (2008) to account for asymmetric features manifest as buoyant, rotating updrafts. According to that paradigm, intensification follows the merger and symmetrization of vertical vorticity associated with those updrafts. The resulting vortex structure aids intensification via concentrated near-surface convergence and latent heat release within a closed circulation (Van Sang et al. 2008; Smith et al. 2017). Sheared TCs are characterized by asymmetric moisture distributions and asymmetric secondary circulations (Reasor et al. 2013; DeHart et al. 2014; Rios-Berrios and Torn 2017), which may influence the symmetrization process or may hinder the feedback between near-surface convergence and latent heat release (e.g., Molinari et al. 2004, 2013).

Existing theories can be expanded to VWS scenarios by hypothesizing that sheared TCs must overcome the effects of VWS (e.g., tilt, asymmetric precipitation) in order to establish robust tangential and overturning circulations capable of driving intensification. Molinari et al. (2004) identified such evolution from aircraft observations of Hurricane Danny (1997) under shear magnitudes between 5 and $11 \mathrm{~m} \mathrm{~s}^{-1}$. Intensification happened when individual rotating updrafts merged into a dominant surface vortex and the equivalent potential temperature $\theta_{e}$ exhibited a dramatic radial gradient. Their results led to the proposal of a two-stage process explaining intensification under VWS. During the first stage, the asymmetric TC is characterized by buoyant updrafts as well as strong downdrafts that flood the boundary layer with cool, dry air. Intensification happens during the second stage because near-surface convergence and deep latent heat release happen within the high $-\theta_{e}$ region of a symmetric, closed surface circulation.

Although this two-stage process has not been further explored, other studies agree that symmetrization of precipitation is a key process preceding intensification under moderate VWS. Sheared TCs are characterized by a wavenumber- 1 precipitation asymmetry, with updrafts dominating in the downshear half and downdrafts in the upshear half (Corbosiero and Molinari 2002; Chen et al. 2006; Hence and Houze 2011; Reasor et al. 2013; DeHart et al. 2014). Consequently, an azimuthal extension of precipitation from downshear to upshear is a hallmark of intensifying TCs under moderate VWS
(Rappin and Nolan 2012; Ge et al. 2013; Onderlinde and Nolan 2014, 2016; Tao and Zhang 2014; Finocchio et al. 2016; Rios-Berrios et al. 2016a; Zawislak et al. 2016; Nguyen et al. 2017). Such extension is often preceded by deep convective updrafts in the upshear-left quadrant (e.g., Stevenson et al. 2014; Chen and Gopalakrishnan 2015; Rogers et al. 2016; Rios-Berrios et al. 2016b,a; Smith et al. 2017; Wadler et al. 2018). An outstanding issue is what drives symmetrization; possible explanations include vortex alignment (e.g., Zhang and Tao 2013) or humidification of the upshear half (e.g., Rios-Berrios et al. 2016a; Rios-Berrios and Torn 2017). However, those processes could be the result —rather than the cause—of the azimuthal extension of precipitation.

Another outstanding issue, not accounted for in the two-stage process of Molinari et al. (2004), is the role of vortex tilt during intensity changes of sheared TCs. Vortex tilt emerges after the center of circulation is displaced along a vertical axis by the sheared environmental flow. This VWS effect limits ascent above the lower-tropospheric center of circulation via thermodynamic stabilization (Jones 1995; DeMaria 1996) or via cool, dry air fluxes (Riemer et al. 2010; Tang and Emanuel 2012; Riemer and Laliberté 2015). Consequently, another hallmark of intensifying TCs under moderate VWS is a small vortex tilt (Davis et al. 2008; Reasor and Eastin 2012; Rappin and Nolan 2012; Ge et al. 2013; Zhang and Tao 2013; Onderlinde and Nolan 2014; Tao and Zhang 2014; Finocchio et al. 2016; Munsell et al. 2017; Leighton et al. 2018). In some cases, however, intensification begins when the vortex is tilted (e.g., Raymond and López Carrillo 2011; Stevenson et al. 2014; Rios-Berrios et al. 2016b) or when a new, vertically aligned vortex emerges within shear-organized convection (Molinari et al. 2004, 2006; Davis et al. 2008; Molinari and Vollaro 2010; Nguyen and Molinari 2015). Those discrepancies suggest that not all TCs follow the same pathway to intensification under moderate shear or that intensification is favored by a combination of factors including, but not limited to, a small vortex tilt. Explaining how and why a TC vortex realigns, remains vertically aligned, or reforms under VWS is of utmost importance (Jones 1995; Reasor et al. 2004; Reasor and Montgomery 2015; Elsberry and Park 2017; Rogers et al. 2017). Equally important is clarifying why intensification is more likely when the vortex is aligned than when it is tilted.

These open issues motivate this study, with the purpose of diagnosing physical processes preceding TC intensification under moderate VWS. An ensemble of idealized simulations, described in section 2, was employed to diagnose processes from multiple realizations of the same TC with prescribed environmental conditions and without complexities added by external factors 
(e.g., upper-tropospheric disturbances, land interactions). The ensemble confirms that small vortex tilt and symmetric precipitation are necessary conditions for intensification (section 3). A detailed analysis focused on a midtropospheric vorticity maximum (section 4 ), shows a two-stage process akin to the hypothesis of Molinari et al. (2004) combined with the vortex merger paradigm of Van Sang et al. (2008). The results lead to the hypothesis (section 5) that intensification in sheared environments follows after deep updrafts initiate a "restructuring" process, consisting of a transition from strong, yet asymmetric ascent in the vicinity of a midtropospheric vortex to nearly symmetric ascent within a vertically aligned, closed circulation. Intensification follows thereafter because the resulting TC structure promotes a feedback between near-surface convergence and ascent within a closed circulation.

\section{Methods}

\section{a. Experimental setup}

An idealized modeling framework was employed following previous studies on TC-VWS interactions (e.g., Nolan 2011; Zhang and Tao 2013; Onderlinde and Nolan 2014; Tao and Zhang 2014, 2015; Finocchio et al. 2016). The initial conditions contained a weak warm-core vortex embedded in a horizontally homogenous sheared environment. The radial profile of tangential wind $v$ was specified via a modified Rankine vortex profile:

$$
v(r)=\left\{\begin{array}{ccc}
v_{m} \frac{r}{R_{m}}, & \text { if } \quad r \leq R_{m} \\
v_{m}\left(\frac{R_{m}}{r}\right)^{\alpha}, & \text { if } & r>R_{m}
\end{array},\right.
$$

where $v_{m}$ is the maximum tangential wind, $R_{m}$ is the radius of maximum wind, $r$ is radial distance from the vortex center, and $\alpha$ is a parameter that controls the tangential wind decay outside $R_{m}$. A weak TC vortex was specified with $v_{m}=15 \mathrm{~m} \mathrm{~s}^{-1}, R_{m}=135 \mathrm{~km}$ at $1.5-\mathrm{km}$ height, and $\alpha=0.4$. A Gaussian decay function was used for the vertical structure of $v$ above and below $1.5 \mathrm{~km}$. Environmental conditions were specified with a moist tropical sounding (Dunion 2011) and the following idealized profile of environmental zonal winds (Nolan 2011; Finocchio et al. 2016):

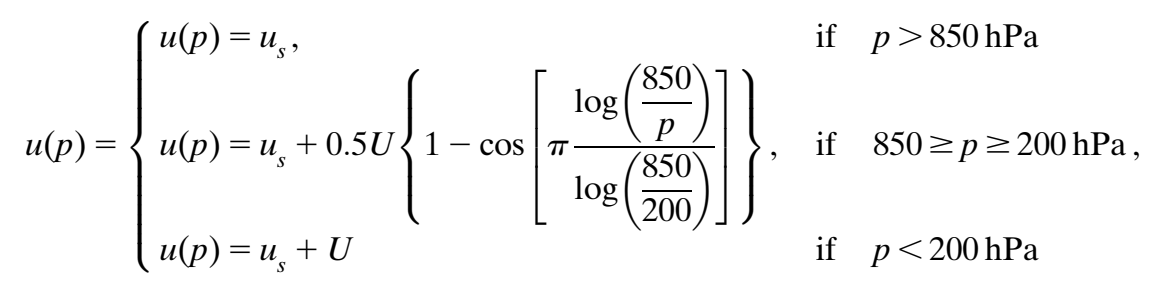

where $u$ is zonal wind, $u_{s}$ is the surface zonal wind, $U$ is the $200-850-\mathrm{hPa}$ zonal shear, and $p$ is pressure.

Simulations with the modified Rankine vortex were integrated forward using the Weather Research and Forecasting (WRF; Skamarock et al. 2008) Model, version 3.4.1. Three nested domains were used with grid spacing of 18,6 , and $2 \mathrm{~km}$, respectively, and horizontal domains of $4320 \mathrm{~km} \times 4320 \mathrm{~km}, 2160 \mathrm{~km} \times 2160 \mathrm{~km}$, and $720 \mathrm{~km} \times 720 \mathrm{~km}$, respectively. Both innermost domains followed the TC throughout the simulation. All domains contained 40 vertical levels with a model top around $56 \mathrm{hPa}$. Several tests with different domain sizes and vertical resolutions showed only small sensitivities to those specifications. A cumulus parameterization was not used in any domain because the 2-km domain covered the main region of precipitation. Radiative feedbacks were not included, but a forthcoming publication will explore the sensitivity of results to radiation. All other physics parameterizations are listed in Table 1.
Environmental winds were kept constant during the integration to isolate structural changes of a TC-like vortex within a specific environment. Nolan (2011) introduced the point downscaling method, which keeps constant environmental winds by applying the Coriolis torque only onto the perturbation winds. Point downscaling was applied here, in combination with analysis nudging, to retain the initial environmental wind profile in the $18-\mathrm{km}$ domain, while allowing all fields to evolve in the 6- and 2-km domains. A drawback of this method is that the environment is not adjusted for thermal wind balance. Another drawback is that constant wind profiles are not realistic representations of observed TC environments (Rios-Berrios and Torn 2017); however, constant wind profiles were used here to eliminate processes associated with the evolving environment. TC intensification within temporally evolving environments should be explored in the future to confirm the findings of this work in a more realistic framework. 
TABLE 1. Physics parameterizations employed in the WRF idealized simulations.

\begin{tabular}{lc}
\hline \hline \multicolumn{1}{c}{ Parameterization } & Reference \\
\hline $\begin{array}{l}\text { WRF single-moment 6-class (WSM6) } \\
\text { microphysics }\end{array}$ & Hong et al. (2004) \\
$\begin{array}{l}\text { Yonsei University (YSU) planetary } \\
\text { boundary layer }\end{array}$ & Hong et al. (2006) \\
\begin{tabular}{l} 
Similarity theory surface model \\
\hline
\end{tabular} & Skamarock et al. (2008) \\
\hline
\end{tabular}

An ensemble of 20 idealized simulations was generated to account for variability in the timing of intensification. Zhang and Tao (2013) demonstrated that, in a similar modeling setup as employed here, the timing of intensification varies substantially under moderate VWS magnitudes. Their approach-following from Van Sang et al. (2008)—was used here to generate the ensemble with uncorrelated, random perturbations sampled from a uniform distribution of water vapor mixing ratio between -0.5 and $0.5 \mathrm{~g} \mathrm{~kg}^{-1}$. Random perturbations were added only below $950 \mathrm{hPa}$ and within the 2 -km domain. All members used the same background conditions specified by Zhang and Tao (2013): $27^{\circ} \mathrm{C}$ sea surface temperature everywhere, constant planetary vorticity corresponding to $20^{\circ} \mathrm{N}, 5 \mathrm{~m} \mathrm{~s}^{-1}$ westerly VWS, and $2 \mathrm{~m} \mathrm{~s}^{-1}$ easterly surface wind. This shear magnitude is at the lower end of moderate VWS (Rios-Berrios and Torn 2017), but larger magnitudes preclude intensification in this modeling setup (Zhang and Tao 2013). Because of the westerly shear, storm-relative quadrants will represent the following: downshear right (DR) is southeast, downshear left (DL) is northeast, upshear left (UL) is northwest, and upshear right (UR) is southwest of the domain center.

\section{b. Tracking algorithm}

A fundamental aspect of this study was the tracking of precipitation and vorticity features in each ensemble member. Multiple tracking methods exist with their advantages and disadvantages (Nguyen et al. 2014; Ryglicki and Hart 2015). Extensive testing with different methods, variables, and ensemble members revealed that most algorithms were sensitive to the initial guess and area of integration. Instead, an object-based algorithm was developed following tracking methods of precipitation features in convectionpermitting models (Davis et al. 2006). A sequence of three steps was followed: 1) smoothing with a nine-point average method, 2) filtering by retaining only the top $5 \%$ of a variable of interest, and 3) finding a centroid via

$$
\mathbf{x}^{\prime}=\frac{\int_{x} \int_{y} \Lambda \mathbf{x} d x d y}{\int_{x} \int_{y} \Lambda d x d y},
$$

where $\mathbf{x}^{\prime}$ is the centroid position vector, $\mathbf{x}$ is a position vector of each grid point, and $\Lambda$ is the variable of interest (e.g., vorticity or total condensate). These steps and thresholds yielded robust results when tracking vorticity features at different levels and between different ensemble members. The centroid position was used as the center of circulation when tracking vorticity or as the precipitation center when tracking total condensate.

\section{c. Vorticity budget}

Intensity changes were diagnosed with an areaaveraged vorticity budget (Davis and Galarneau 2009). Although multiple metrics could diagnose TC intensity, area-averaged vorticity was used here because of the important evolution of various vorticity features before and during intensification. In this budget, the temporal rate of change of area-averaged vorticity $\tilde{\zeta}$ is given by

$$
\begin{aligned}
\frac{\partial \tilde{\zeta}}{\partial t}= & -\bar{\eta} \tilde{\delta}-\frac{1}{A} \oint \eta^{\prime} \mathbf{V}_{h}^{\prime} \cdot \hat{n} d l+\frac{1}{A} \oint \omega\left(\hat{k} \times \frac{\partial \mathbf{V}_{h}}{\partial p}\right) \cdot \hat{n} d l \\
& -\frac{1}{A} \oint\left(\hat{k} \times \mathbf{F}_{r}\right) \cdot \hat{n} d l,
\end{aligned}
$$

where $\eta$ is absolute vorticity, $\tilde{\delta}$ is area-averaged divergence, $\mathbf{V}_{h}$ is the horizontal vortex-relative wind vector, $\omega$ is vertical velocity on isobaric coordinates, $\mathbf{F}_{r}$ is friction, and $A$ is the area of a box centered on a feature of interest. Spatial integration involves a closed integral along the box; therefore, $\hat{n}$ represents a vector perpendicular to the box segments, an overbar represents a mean along the box, and a prime symbol represents a perturbation from that mean. This partition separates the flux divergence of absolute vorticity into a mean stretching term, represented by the first term on the righthand side, and an eddy vorticity flux, represented by the second term. Compared to the more traditional nonflux form of the vorticity equation, the first two terms include the contributions of vortex stretching and horizontal advection, while the third term combines vertical advection and tilting into a "tilting" term that depends on the correlations between vertical motions and horizontal vorticity (Davis and Galarneau 2009). The fourth term represents frictional dissipation, which was approximated by the subgrid-scale mixing momentum tendencies. This term was combined with mean stretching because of their similar magnitudes of opposite signs near the surface; their combined contribution will be called net mean stretching. All terms were calculated with 6-min output after removing the motions of the 2-km domain and the feature of interest. Similar to Davis and Galarneau (2009), an ensemble of budgets was obtained by moving the integration box five grid points in each direction to account for box size and position variability. 


\section{General overview of the simulations}

Consistent with the findings of Zhang and Tao (2013), the ensemble simulates an intensifying TC with large variability in the timing of intensification (Fig. 1a). All members exhibit a gradual intensification during the first $48 \mathrm{~h}$, followed by a period of nearly steady-state intensity. Ensemble members diverge after $96 \mathrm{~h}$ when some members simulate rapid intensification, whereas other members simulate steady-state intensity. All members ultimately simulate rapid intensification, but there is substantial variability around the onset of intensification. Following Judt and Chen (2016), the onset was defined as the first lead time that met two criteria: 1) the intensity over the following $24 \mathrm{~h}$ increased by at least $15.1 \mathrm{~m} \mathrm{~s}^{-1}$ and 2) the intensity over the following $6 \mathrm{~h}$ increased by at least $3.8 \mathrm{~m} \mathrm{~s}^{-1}$ (nearly equivalent to a continuous intensification of $15.1 \mathrm{~m} \mathrm{~s}^{-1}$ in $24 \mathrm{~h}$ ). Within the ensemble, the objectively determined onset happens anywhere between 97 and $130 \mathrm{~h}$ (black dots in Fig. 1a). Despite this variability, all members cluster together after intensifying and reaching their maximum simulated intensity by $192 \mathrm{~h}$.

The large variability in the onset of intensification offers an opportunity to explore why some members simulate intensification earlier than others. Following the approach of Zhang and Tao (2013), this issue was investigated by comparing two members that predict the earliest and latest onset of intensification (early and late members hereafter). This comparison revealed that their main difference was the timing of symmetrization of precipitation (Fig. 2). Domain-centered plots of composite reflectivity show that precipitation initially organizes in the downshear half of the simulated TCs (Figs. 2a,e), followed by a cyclonic motion around a lower-tropospheric center of circulation (Figs. 2b,f). These members diverge from each other as precipitation moves through the downshear-left quadrant; precipitation moves faster and, consequently, reaches upshear left sooner in the early member than in the late member (Figs. 2c,g). Shortly after precipitation reaches upshear left, the early member is characterized by nearly symmetric precipitation (Fig. 2d). The late member, however, is still highly asymmetric by $102 \mathrm{~h}$ (Fig. 2h). Intensification begins quickly after precipitation transitions from an upshear-left maximum to a nearly symmetric distribution.

This transition is consistent for all members as quantified by the symmetricity metric. Symmetricity $S$ is defined here as the percentage of azimuths with light precipitation, or

$$
S(t)=100 \times \frac{\sum_{i=0}^{N} \lambda^{i}(t)}{N},
$$

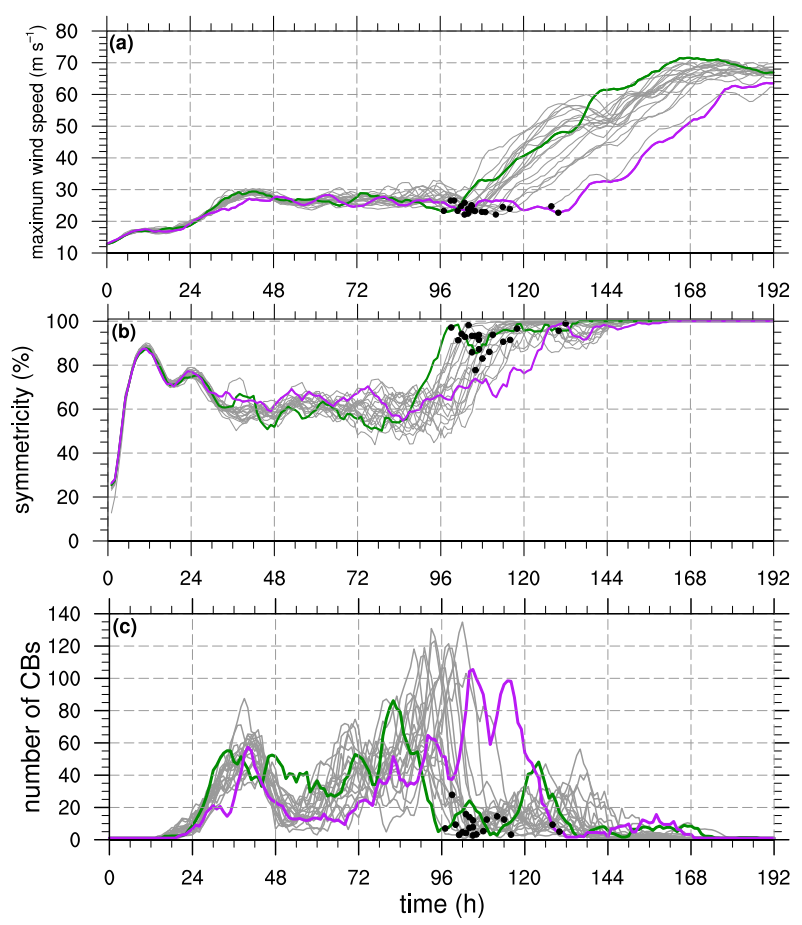

FIG. 1. Time series of (a) maximum 10-m wind speed, (b) symmetricity, and (c) number of convective bursts (CBs) after applying a 6-h running mean for each ensemble member (gray), the early member (green), and the late member (purple). Dots indicate the onset of intensification. See text for details about symmetricity and CBs.

where $N$ is the total number of azimuthal bins and $\lambda^{i}$ is the number of azimuthal bins with composite reflectivity of the lowest $1.5 \mathrm{~km}$ exceeding $20 \mathrm{dBZ}$. This threshold was chosen after extensive tests revealed that symmetrization happened because of light, not convective, precipitation. Figure $1 \mathrm{~b}$ shows time series of $S$ evaluated within 1.5 times the radius of maximum azimuthally averaged winds at each lead time. Small values, such as those seen after $24 \mathrm{~h}$, represent asymmetric precipitation, whereas values close to unity represent nearly symmetric precipitation. The key feature of Fig. $1 \mathrm{~b}$ is that the variability of $S$ resembles the variability of intensity: the onset of intensification follows after $S$ increases and exceeds $75 \%$ in all members, but the early member is the first and the late member is the last to transition into nearly symmetric precipitation.

The different precipitation evolutions are related to different tilt evolutions. Vortex tilt was diagnosed via the distance between the lower- and midtropospheric centers of circulation determined from the objecttracking method described in section 2. The lowertropospheric center was tracked at $900 \mathrm{hPa}$, whereas the midtropospheric center was tracked at $400 \mathrm{hPa}$ because that level was characterized by a clear vorticity maximum within precipitation (not shown). Figure $3 \mathrm{a}$ 

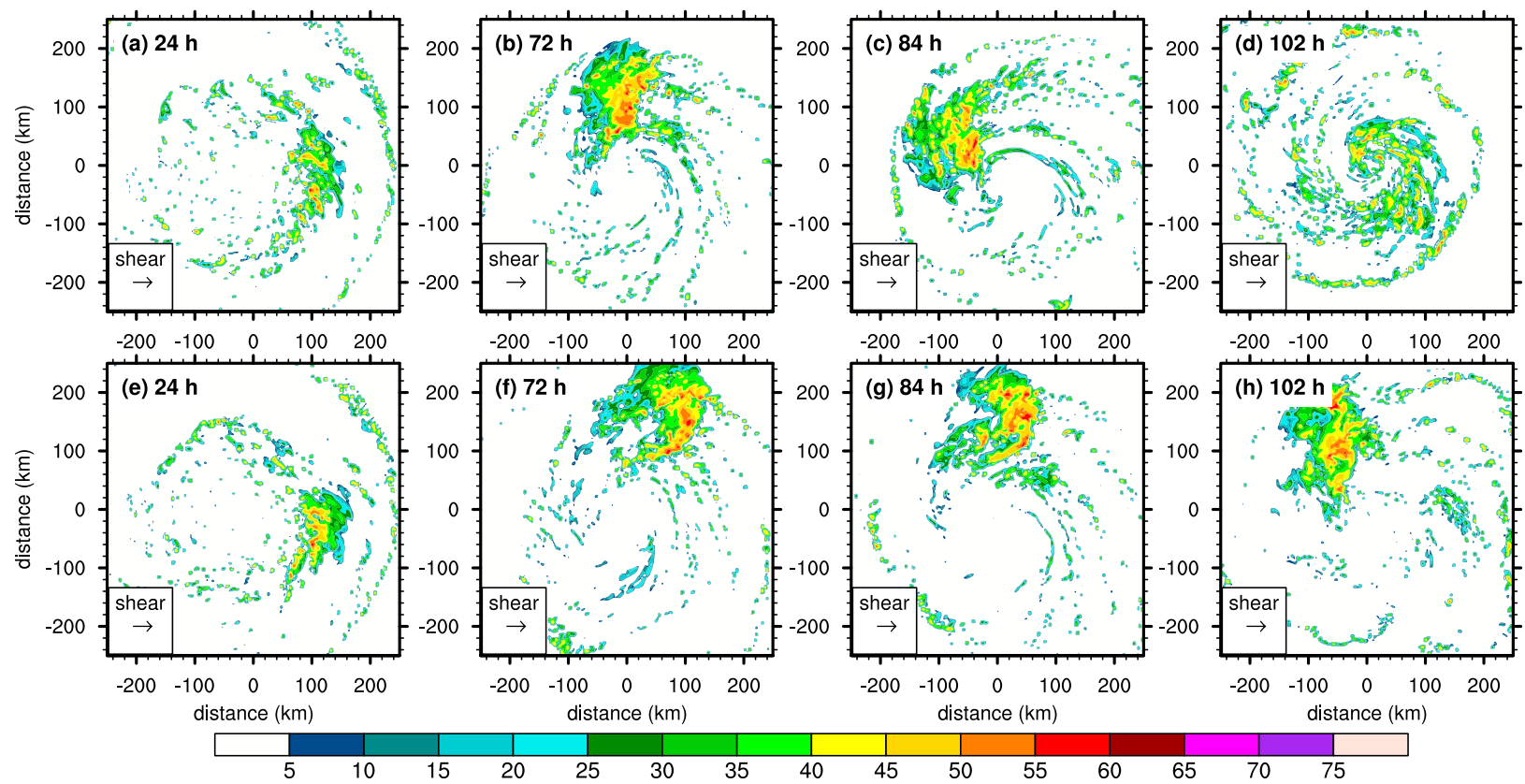

distance $(\mathrm{km})$

\begin{tabular}{lc|c|c} 
& & & \\
30 & 35 & $40 \quad 45$ \\
composite reflectivity (dBZ)
\end{tabular}

FIG. 2. Domain-centered simulated composite reflectivity below $1.5 \mathrm{~km}$ (shading; every $5 \mathrm{dBZ}$ ) for (a)-(d) the early and (e)-(h) the late members. Panels show (a),(e) 24, (b),(f) 72, (c),(g) 84, and (d),(h) $102 \mathrm{~h}$. Shear direction is indicated at the lower-left corner of each panel.

shows the evolution of 400-900-hPa tilt after applying a 6-h running mean to remove short-term variability. All members simulate increasing tilt magnitude during the first $24 \mathrm{~h}$, which corresponds to the timing of convective organization in the downshear half (Figs. 2a,e). After $24 \mathrm{~h}$, the midtropospheric vortex begins an azimuthal motion through the downshear-left quadrant. The early and the late members diverge after $24 \mathrm{~h}$ when the midtropospheric vortex remains radially closer to the lowertropospheric center in the early than in the late member.
This small difference grows over time such that the early member reaches upshear left approximately $26 \mathrm{~h}$ earlier than in the late member ( 72 vs $98 \mathrm{~h}$ ). The tilt magnitude quickly decreases thereafter until reaching a minimum just before the onset of intensification.

All members depict the same tilt evolution, albeit with different azimuthal motions through the downshear-left quadrant. This result is illustrated in Fig. 3b, which compares the onset of intensification against the duration of downshear-left tilt (defined as a mathematical tilt
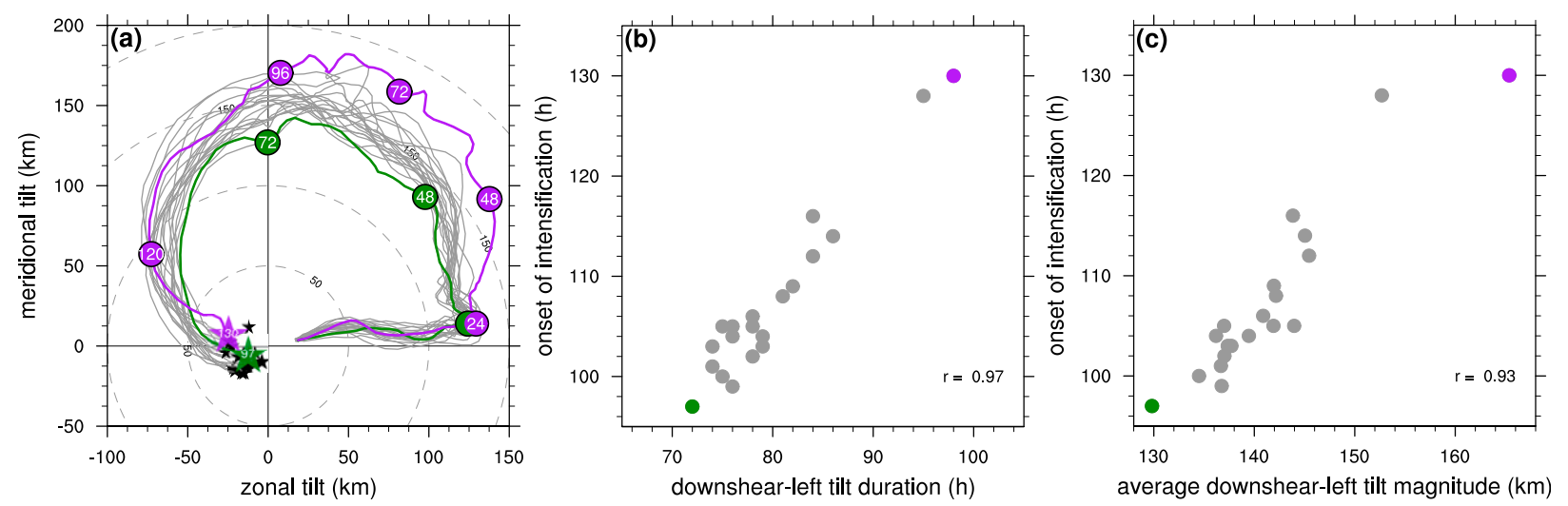

FIG. 3. (a) Evolution of the 400-900-hPa tilt vector after applying a 6-h running mean from $1 \mathrm{~h}$ until the onset of intensification of each member. Dots appear every $24 \mathrm{~h}$, dashed circles are every $50 \mathrm{~km}$, and stars appear at the onset of intensification of each member. (b),(c) Comparison of onset of intensification against (b) duration and (c) average magnitude of downshear left tilt (defined as a mathematical tilt angle between $0^{\circ}$ and $90^{\circ}$ ). Colors are as in Fig. 1. 
angle between $0^{\circ}$ and $90^{\circ}$ ). A strong correlation exists between those two quantities (Pearson's correlation coefficient of 0.97). The duration of downshear-left tilt depends on the average downshear-left tilt magnitude, resulting in a strong correlation between the onset of intensification and the average downshear-left tilt magnitude (Pearson's correlation coefficient of 0.93; Fig. 3c). In this study, tilt magnitude depends on the initial location of downshear convective organization, which randomly varies between members because of the initial boundary layer water vapor perturbations. Members with convective organization closer to the lower-tropospheric center of circulation develop smaller downshear-left tilts for shorter durations, thus leading to earlier onsets of intensification (Figs. 3b,c). This study will not explore the mechanisms governing the azimuthal tilt motion through the downshear-left quadrant; instead, the analysis will focus on the upshear-left tilt reduction that happens over a 24-32-h period in all members despite their different downshear-left tilts.

Previous modeling studies also identified symmetrization of precipitation and tilt reduction as necessary for intensification (e.g., Ge et al. 2013; Zhang and Tao 2013; Onderlinde and Nolan 2014; Tao and Zhang 2014, 2015; Finocchio et al. 2016; Munsell et al. 2017); however, the following questions remain unanswered:

- Why are upshear-left precipitation and tilt important for intensification?

- What drives the symmetrization of precipitation and vortex tilt reduction?

- Why is the symmetric, aligned structure more conducive to intensification than the asymmetric, tilted structure?

The remainder of this manuscript will address these questions by explaining the physical processes promoting intensification under moderate VWS. The early and the late members will be used as illustrative members, but their results will be generalized with ensemble statistics.

\section{Diagnosis of physical mechanisms}

A key aspect of the idealized simulations is the coevolution of precipitation and a midtropospheric vorticity maximum. This coevolution, hinted by the symmetricity and tilt diagnostics, was confirmed with a time-azimuth framework depicting averaged variables within a $50-\mathrm{km}$ ring located at the radial position of the precipitation centroid at each lead time (Fig. 4). A region of positive $400-\mathrm{hPa}$ absolute vorticity is collocated with the asymmetric precipitation before the onset of intensification.
Both fields undergo a similar evolution: A maximum first appears downshear, gradually moves through the downshear-left quadrant, accelerates in the upshear-left quadrant, and finally spreads over all azimuths just before the onset of intensification (Figs. 4a,c,e). This evolution happens faster in the early member than in the late member, especially because of their different evolutions through the downshear-left quadrant (Figs. 4a,c). An ensemble mean with respect to the onset of intensification confirms that tilt reduction and symmetrization happen in unison during the $24 \mathrm{~h}$ preceding intensification of all members (Fig. 4e).

The midtropospheric vorticity maximum emerges as a separate entity within the shear-organized convection. This result is illustrated in Fig. 5 through cross sections of 6-hourly averaged vorticity and diabatic heating along a line passing through both the lower-tropospheric and midtropospheric centers of circulation of the early member. A small-scale, nearly aligned vortex first appears within a region of large diabatic heating located $100 \mathrm{~km}$ away from the lower-tropospheric center (Fig. 5a). The small-scale vortex weakens in the lower troposphere, but a conglomerate of small-scale, positive vorticity remains with peak values around $400 \mathrm{hPa}$ and latent heat release over a deep layer (Fig. 5b). This conglomerate of vorticity forms a mesoscale midtropospheric vortex that is detected by the tilt vector as it travels azimuthally around the lower-tropospheric center (cf. Fig. 3a); however, this midtropospheric vortex is not directly connected to the main TC vortex in the sense of a single tilted "cylinder." The midtropospheric vortex persists and strengthens upon reaching upshear left (Fig. 5c), followed by a transition to a single vertically aligned vortex before the onset of intensification (Fig. 5d).

Although environmental shear induces storm-scale asymmetries in strong TCs (Corbosiero and Molinari 2002; Chen et al. 2006; Reasor et al. 2013; DeHart et al. 2014), our simulations suggest that a midtropospheric vortex modulates asymmetries in weak, sheared TCs. In addition to the vorticity and precipitation asymmetries before intensification, clear moisture asymmetries also exist as demonstrated by the vertically integrated saturation fraction (Figs. 4b,d,f). Near-saturated air only exists in the vicinity of the midtropospheric vorticity maximum and its associated precipitation. All other regions remain dry until symmetrization, after which time all azimuths become nearly saturated within the $50-\mathrm{km}$ ring centered on the precipitation centroid of each member (Fig. 4f). Other kinematic and thermodynamic fields are also modulated by the presence (or lack) of the midtropospheric vortex in each quadrant (not shown), which agrees with the tilt-relative circulations identified by Jones (1995). 

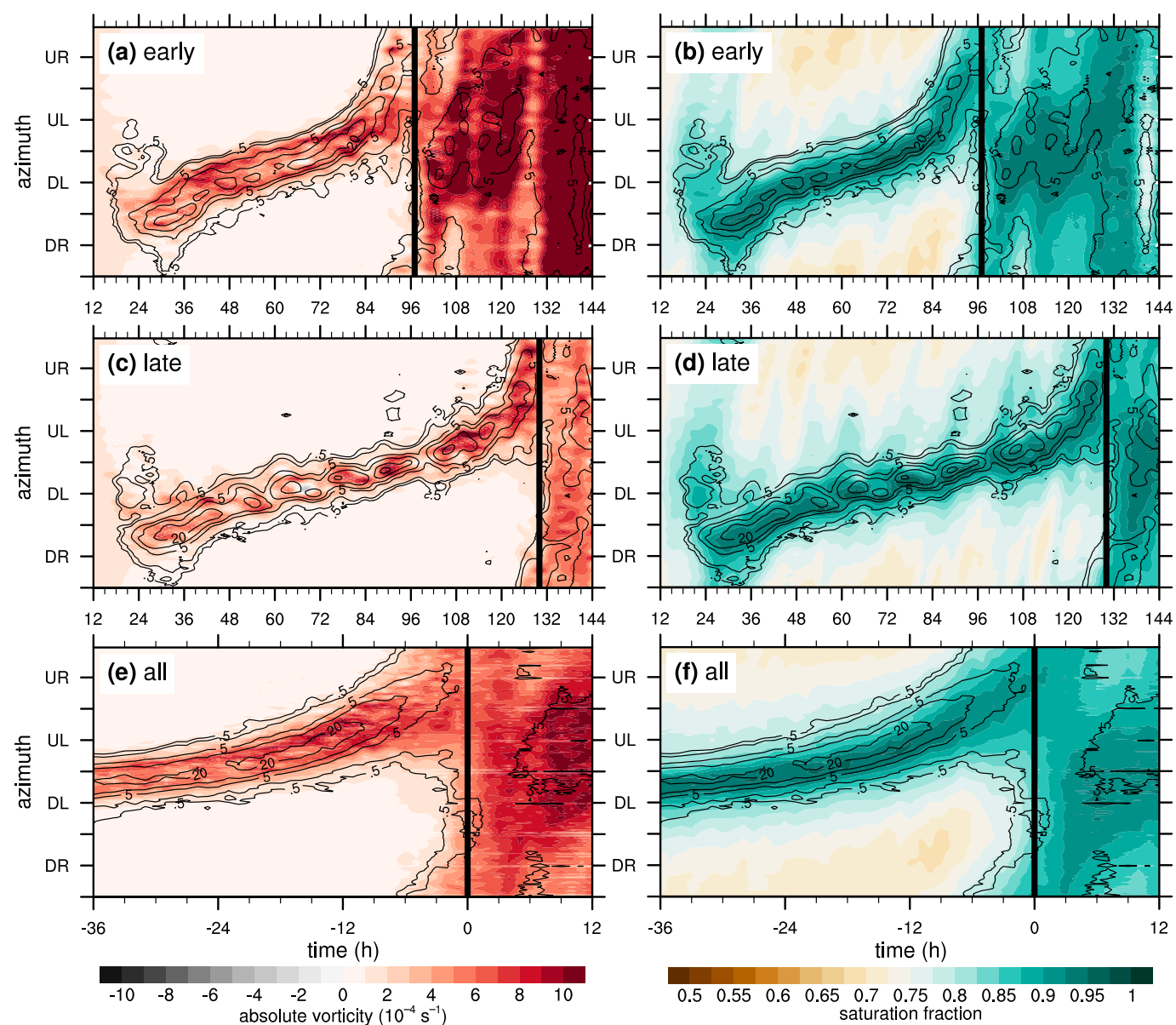

FIG. 4. Azimuth-time evolution of (a),(c),(e) 400-hPa absolute vorticity (shading; every $1 \times 10^{-4} \mathrm{~s}^{-1}$ ); (b),(d),(f) saturation fraction (shading; every 0.025); and total column condensate (contours; plotted at 0.5, 1.0, 5.0, 10.0 , and $20.0 \mathrm{~mm}$ ) averaged within a 50-km-wide ring centered on the total column rain centroid for (a),(b) the early member, (c),(d) the late member, and (e),(f) the ensemble mean with respect to the onset of each member. Thick black lines mark the onset of intensification. A 6-h running mean was applied. Azimuths are defined with respect to the

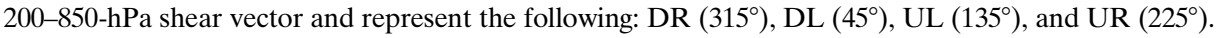

\section{a. Midtropospheric vortex structure and evolution}

The aforementioned findings motivate an analysis of the structure and evolution of the midtropospheric vortex to elucidate why its arrival to upshear left precedes intensification. To this end, a pressure-time framework was employed to diagnose area-averaged quantities within a $50-\mathrm{km}$ radius of the midtropospheric vortex. That area captures the main region of evolving precipitation and vorticity, while considering the midtropospheric vortex separately from the lowertropospheric vortex even though both contribute to the same TC-scale system.

In this framework, the emergence and maintenance of the midtropospheric vortex is evidenced by a mid- to upper-tropospheric vorticity maximum (Fig. 6). Peak vorticity values appear near $400 \mathrm{hPa}$ during $24-84 \mathrm{~h}$ for the early member (Fig. 6a) and $24-108 \mathrm{~h}$ for the late member (Fig. 6b). Nonlinear balanced dynamics predict that such vorticity structure is associated with a cool anomaly below and a warm anomaly above, which in turn forces ascent upwind and descent downwind of the vorticity maximum along the raised isentropes (Raymond 1992; Jones 1995). This thermal structure is indeed evident as shown by area-averaged density potential temperature $\theta_{\rho}$ anomalies $^{1}$ with respect to the main TC vortex (Figs. 6a,c). Warm and cool anomalies appear above and

\footnotetext{
${ }^{1}$ These anomalies represent a departure from the azimuthally averaged $\theta_{\rho}$ with respect to the lower-tropospheric vortex at each lead time. This reference state accounts for the upper-tropospheric warming associated with the evolving TC warm core and for the domain warming in the absence of radiation.
} 


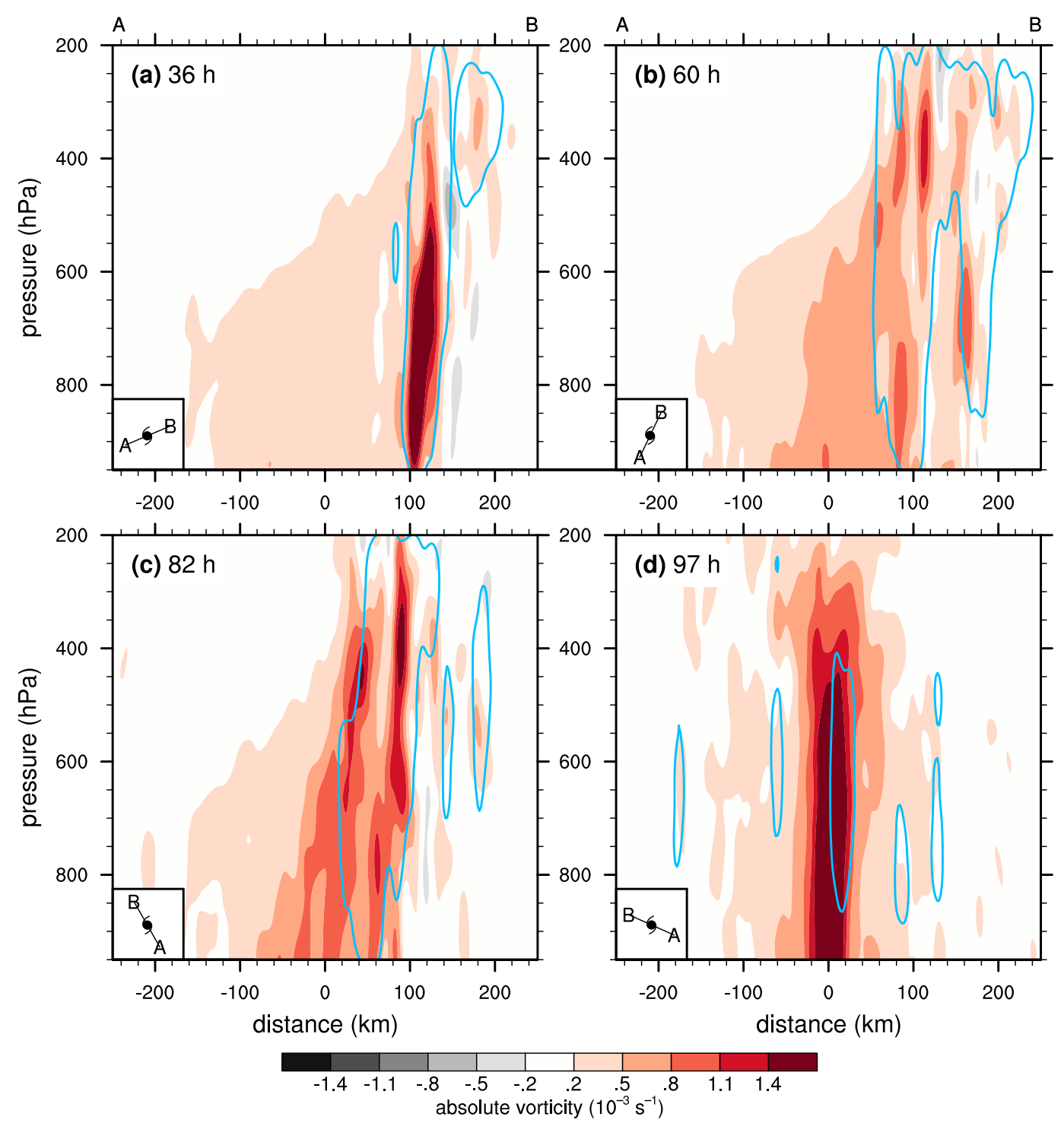

FIG. 5. Vertical cross sections of absolute vorticity (shading; every $0.3 \times 10^{-3} \mathrm{~s}^{-1}$ ) and diabatic heating (contours; only plotted at $5 \mathrm{~K} \mathrm{~h}^{-1}$ ) along the $400-900-\mathrm{hPa}$ tilt vector and centered on the $900-\mathrm{hPa}$ center of circulation of the early member. Distance increases from point A to point B as indicated by the insets on the lower-left corner of each panel. Panels show 6-h-averaged fields with a center time of (a) 36, (b) 60, (c) 82, and (d) $97 \mathrm{~h}$.

below $400 \mathrm{hPa}$, respectively, before the onset of intensification. This general structure, which resembles the structure of mesoscale convective vortices (Houze 2004, and references therein), persists, while the midtropospheric vortex travels through the downshear-left quadrant.

Noteworthy changes happen after the midtropospheric vortex enters upshear left, or 12-24 $\mathrm{h}$ before the onset of intensification (Fig. 6). Vorticity increases first near the level of maximum vorticity, followed by a rapid increase of lower-tropospheric vorticity and a transition to a vorticity maximum near the surface. At the same time, the thermal anomalies weaken or even disappear. These structural changes happen as the TC vortex transitions from tilted to aligned, which suggests that those changes simply represent the decreasing tilt magnitude. However, vertical profiles following the 900-hPa center of circulation also indicate increasing vorticity at all levels (not shown) only after the midtropospheric vortex enters upshear left.

Given the link between the midtropospheric vorticity and precipitation, a possible explanation for the increasing lower-tropospheric vorticity is a change in the vertical mass flux profile. The vertical mass flux profile 

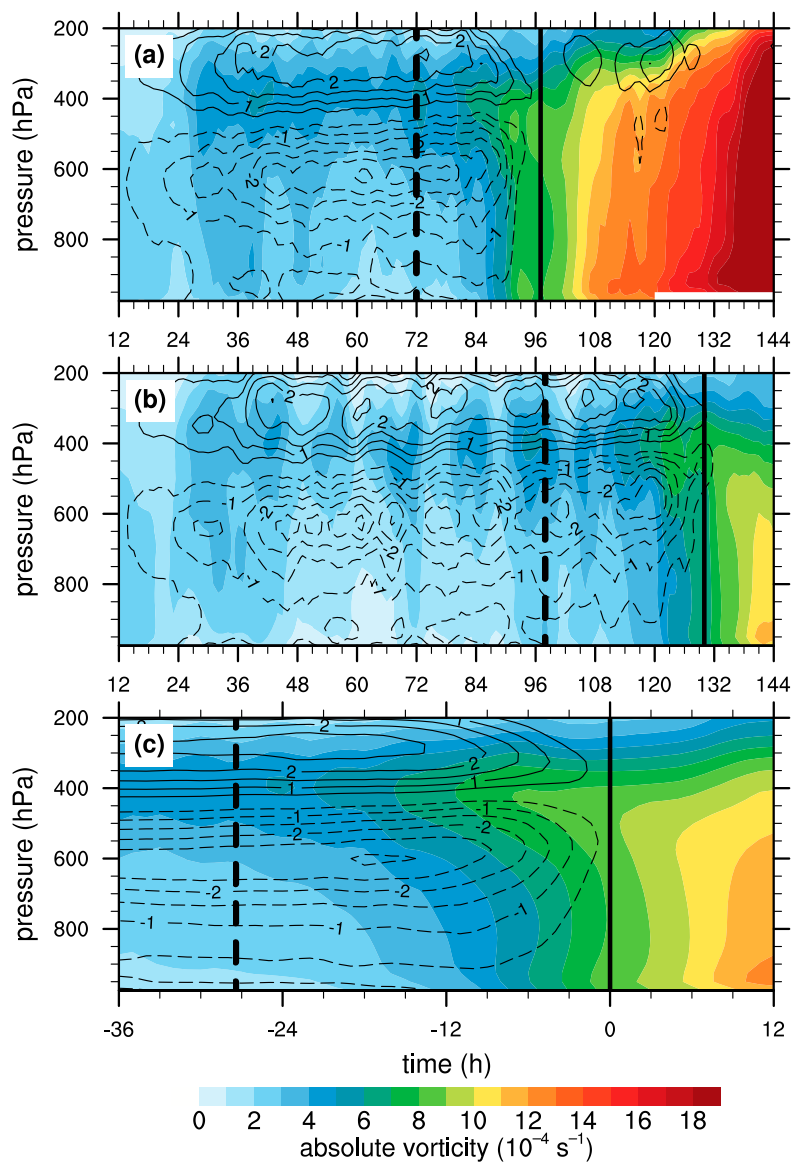

FIG. 6. Pressure-time depiction of absolute vorticity (shading; every $1 \times 10^{-4} \mathrm{~s}^{-1}$ ) and density potential temperature anomaly (contours; every $0.5 \mathrm{~K}$ ) averaged within a $50-\mathrm{km}$ radius from the midtropospheric center of circulation for (a) the early member, (b) the late member, and (c) the ensemble mean with respect to the onset of intensification of each member. Thick solid lines mark the onset of intensification and thick dashed lines mark the arrival of the midtropospheric vortex to upshear left. A 6-h running mean was applied.

relates to vorticity tendencies via the stretching term, which is proportional to divergence or the vertical gradient of the vertical mass flux [Eq. (2)]. A top-heavy profile favors vorticity spinup over a deep layer, whereas a bottom-heavy profile favors vorticity spinup near the surface. A shift from a top-heavy to a bottom-heavy profile happens during tropical cyclogenesis when a lower-tropospheric center of circulation forms from a disturbance with a midtropospheric vorticity maximum (e.g., Raymond and López Carrillo 2011; Gjorgjievska and Raymond 2014; Davis 2015; Tang et al. 2016). Potential explanations for the shift in the vertical mass flux profile include lower-to-midtropospheric stabilization (e.g., Raymond and Sessions 2007) or midtropospheric saturation (e.g., Davis 2015; Tang et al. 2016), both of which are thought to facilitate lower-tropospheric ascent and increasing lower-tropospheric vertical mass flux.

Indeed, the vertical mass flux and $\theta_{e}$ profiles evolve in concert with the midtropospheric vortex. Areaaveraged vertical mass flux $(\rho w)$ profiles are predominantly top heavy when the midtropospheric vortex is downshear left as the maximum flux appears above $600 \mathrm{hPa}$ (Figs. 7a,b). The top-heavy profiles result from a combination of both elevated convection and stratiform precipitation (not shown) possibly in response to the thermodynamic anomalies induced by the midtropospheric vortex. As will be shown later, ascending motions begin cyclonically upwind and maximize above the midtropospheric vortex, whereas descending motions happen below and cyclonically downwind of the midtropospheric vortex. Those downdrafts, in combination with a persistent midtropospheric $\theta_{e}$ minimum (Figs. 7a,b), bring cool, dry air to the boundary layer as typically occurs in sheared TCs (Riemer et al. 2010; Riemer and Laliberté 2015; Alland et al. 2017). The impact of downdrafts is evident in the occasional $\theta_{e}$ reductions below $900 \mathrm{hPa}$, while the midtropospheric vortex travels through downshear left.

Important changes also happen $12-24 \mathrm{~h}$ before the onset of intensification when the midtropospheric vortex enters upshear left (Fig. 7c). Vertical mass fluxes increase below $800 \mathrm{hPa}$ while decreasing aloft, leading to a more bottom-heavy vertical mass flux profile. At the same time, $\theta_{e}$ increases by at least $5 \mathrm{~K}$ especially below $600 \mathrm{hPa}$ (Figs. 7a-c). Relatively high $\theta_{e}$ persists even when the vertical mass flux nearly vanishes and reaches a minimum at the onset of intensification. Such minimum happens as the intensity of precipitation diminishes (cf. Fig. 2d) during the transition from a midtropospheric vorticity maximum and associated thermodynamic anomalies to a single aligned vortex. A recovery happens after the onset, when the strengthening tangential and overturning circulations promote upward vertical mass fluxes and high $\theta_{e}$ in the lower troposphere.

This analysis points at important structural changes after the midtropospheric vortex reaches upshear left. Previous studies of real-world TCs also find that the characteristics of the upshear-left quadrant influence intensification (e.g., Stevenson et al. 2014; Chen and Gopalakrishnan 2015; Rogers et al. 2016; Rios-Berrios et al. 2016b; Nguyen et al. 2017; Smith et al. 2017; RiosBerrios and Torn 2017; Wadler et al. 2018). The reason for the shift in the vertical mass flux and increased $\theta_{e}$ will be explored in section $4 \mathrm{c}$, but first a vorticity budget analysis will confirm the influence of structural changes on the simulated intensification. 

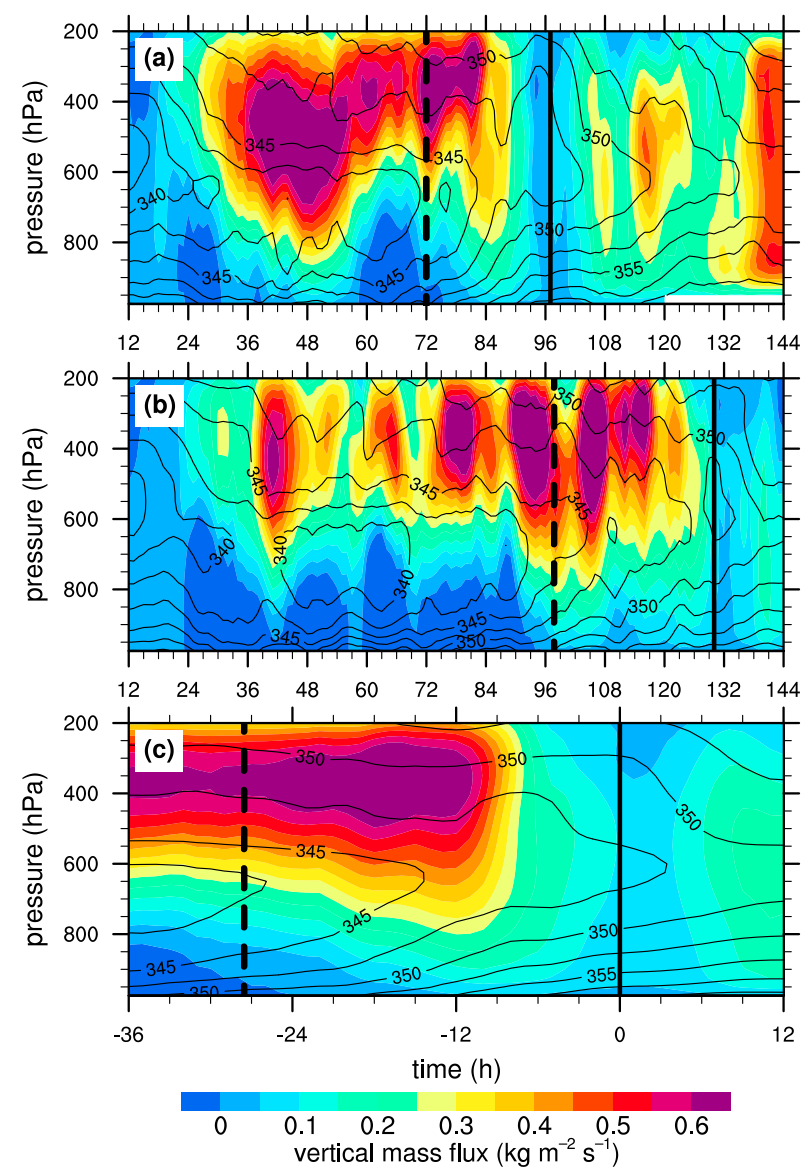

FIG. 7. As in Fig. 6, but for vertical mass flux (shading; every $0.05 \mathrm{~kg} \mathrm{~m}^{-2} \mathrm{~s}^{-1}$ ) and equivalent potential temperature (contours; every $2.5 \mathrm{~K})$.

\section{b. Vorticity budget}

The previous subsection described processes associated with the evolution of the midtropospheric vortex; however, it is unclear how those processes influence intensity changes. Based on the vorticity and vertical mass flux profiles, a potential hypothesis is that the shift from a predominantly top-heavy to a more bottom-heavy mass flux profile represents increased near-surface convergence, which favors vorticity spinup via vortex stretching. This hypothesis was tested through an areaaveraged vorticity budget calculated on a $100 \mathrm{~km} \times$ $100 \mathrm{~km}$ box centered on either the lower- or midtropospheric centers of circulation. The domain size is consistent with the previous analyses and with the radius of maximum winds at the onset of intensification (not shown). Budget calculations with respect to both centers were used to quantify the role of each vortex. Only the early and the late members were considered because high-frequency output was required to balance the budget. All calculations show strong agreement between the actual tendencies (Figs. 8a,b, 9a,b) and the sum of individual tendencies (Figs. 8c,d, 9c,d), thus lending confidence to this analysis.

The vorticity budgets further highlight the role of the midtropospheric vortex before the onset of intensification. Total vorticity tendencies are of comparable magnitude when calculated with respect to either the midtropospheric (Figs. 8a-d) or lower-tropospheric centers (Figs. 9a-d) of both early and late members. A persistent vorticity spinup happens underneath the midtropospheric vortex $12-24 \mathrm{~h}$ before the onset of intensification of both members, or around $84-96 \mathrm{~h}$ in the early member and $108-132 \mathrm{~h}$ in the late member (Figs. 8a-d). A persistent vorticity spinup happens at all levels within the lower-tropospheric vortex only after the onset of intensification (Figs. 9a-d). The main difference between members is that the late member has more frequent periods of negative vorticity tendencies at all levels, which likely weaken and delay the azimuthal motion of its midtropospheric vortex.

Individual tendencies illustrate the processes leading to the persistent vorticity spinup following the midtropospheric vortex (Figs. 8e-j). Consistent with the topheavy vertical mass flux profile before intensification, the net mean stretching term (mean stretching plus friction) depicts persistent vorticity spinup above $850 \mathrm{hPa}$ (Figs. 8e,f). That spinup, however, is partially offset by negative tilting of horizontal vorticity (Figs. 8i,j). Downdrafts collocated with outward horizontal vorticity induced by the main TC vortex, as well as updrafts collocated with inward horizontal vorticity, result in negative tilting when the midtropospheric vortex is downshear left (Fig. 10a). This pattern changes after the midtropospheric vortex enters upshear left, or around $84 \mathrm{~h}$ in the early member and $120 \mathrm{~h}$ in the late member; the tilting term becomes positive (Figs. 8i,j) as inward horizontal vorticity induced by the stronger midtropospheric vortex is collocated with downdrafts (Fig. 10b). At the same time, the net mean stretching substantially increases in the boundary layer (Figs. 8e,f). Despite vorticity spindown via eddy vorticity fluxes (Figs. $8 \mathrm{~g}, \mathrm{~h}$ ), a persistent vorticity spinup happens after $84 \mathrm{~h}$ in the early member and after $120 \mathrm{~h}$ in the late member. That spinup happens through both vorticity convergence and tilting of horizontal vorticity above the boundary layer after the midtropospheric vortex enters upshear left.

Importantly, the substantial and persistent vorticity spinup happens before the 400-900-hPa tilt magnitude reaches a minimum in both the early and the late members (cf. Fig. 3). That vorticity spinup happens locally because of vortex stretching and tilting above the boundary layer and not because of eddy vorticity fluxes as would be expected if the midtropospheric and 

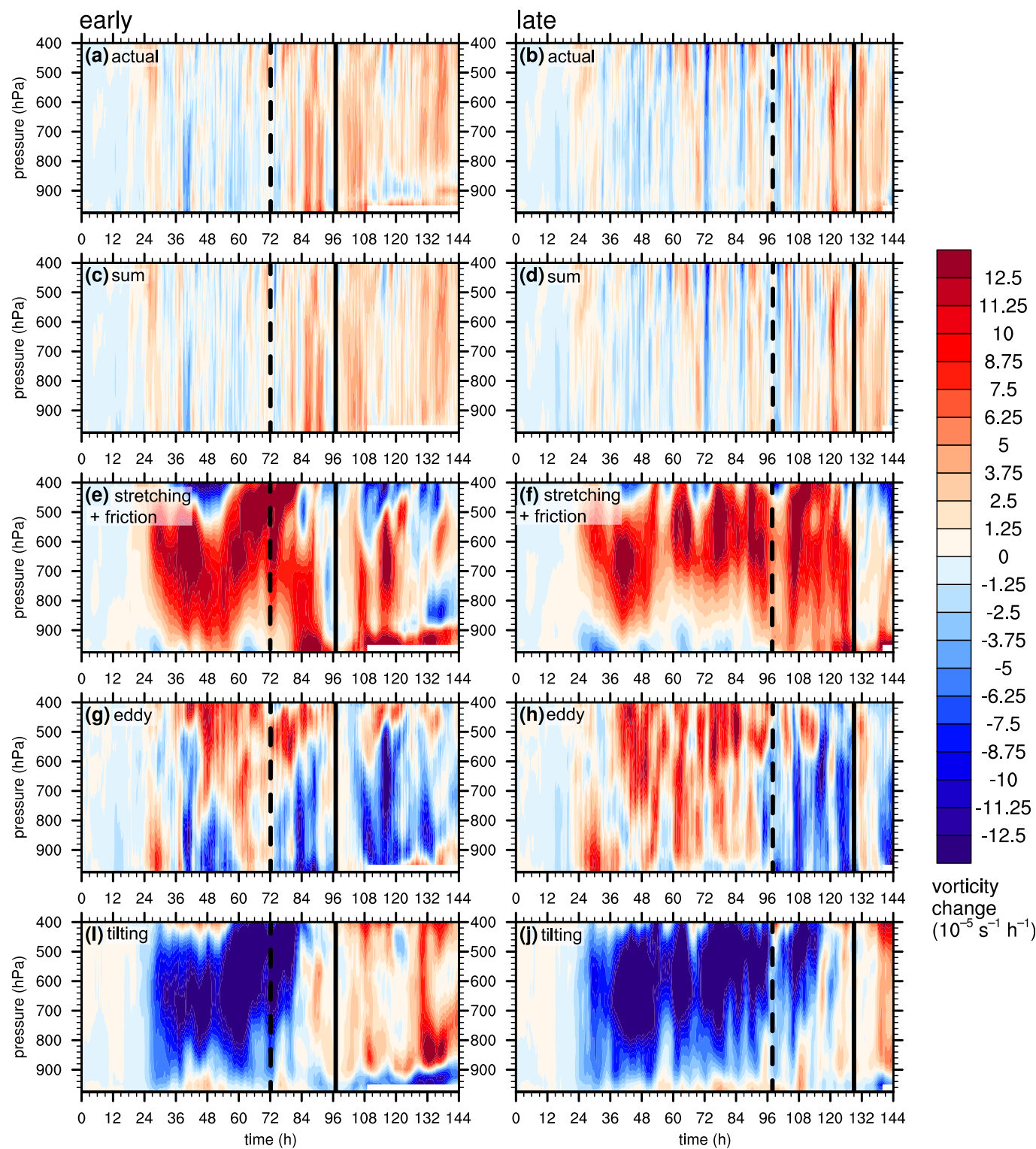

FIG. 8. Pressure-time depiction of area-averaged vorticity tendencies (shading; every $1.25 \times 10^{-5} \mathrm{~s}^{-1}$ ) following the midtropospheric vortex of (a),(c),(e),(g),(i) the early and (b),(d),(f),(h),(j) the late members. Panels show (a),(b) the actual vorticity tendency calculated from center differentiation, (c),(d) the sum of individual tendencies, (e),(f) the combination of mean stretching and friction, (g),(h) eddy vorticity flux, and (i),(j) tilting of horizontal vorticity. Thick solid lines mark the onset of intensification and thick dashed lines mark the arrival of the midtropospheric vortex to upshear left.

lower-tropospheric vortices were aligning through differential vorticity advection. These processes-which also appear in the vorticity budget of observed sheared TCs (Rios-Berrios et al. 2016b,a) — are consistent with a large-ensemble study of TC intensification (Miyamoto and Nolan 2018). A new question emerges from these findings, Is tilt reduction solely a result of advective alignment between the lower- and midtropospheric centers or a result of other processes?
The vorticity budget with respect to the lowertropospheric vortex favors the latter view. A large vorticity spinup happens above $600 \mathrm{hPa}$ after $84 \mathrm{~h}$ of the early member and $120 \mathrm{~h}$ of the late member (Figs. 9a-d). If that midtropospheric vorticity spinup signaled alignment, then the positive tendency should be contributed primarily by eddy fluxes. Integrated tendencies, however, show negative eddy fluxes above $800 \mathrm{hPa}$ except for a brief 6-h period just before the onset (Figs. 9g,h). 


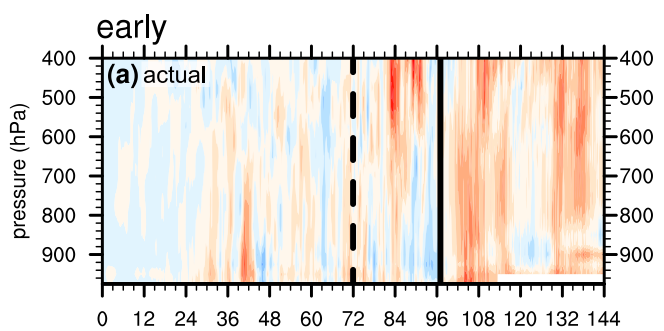

late
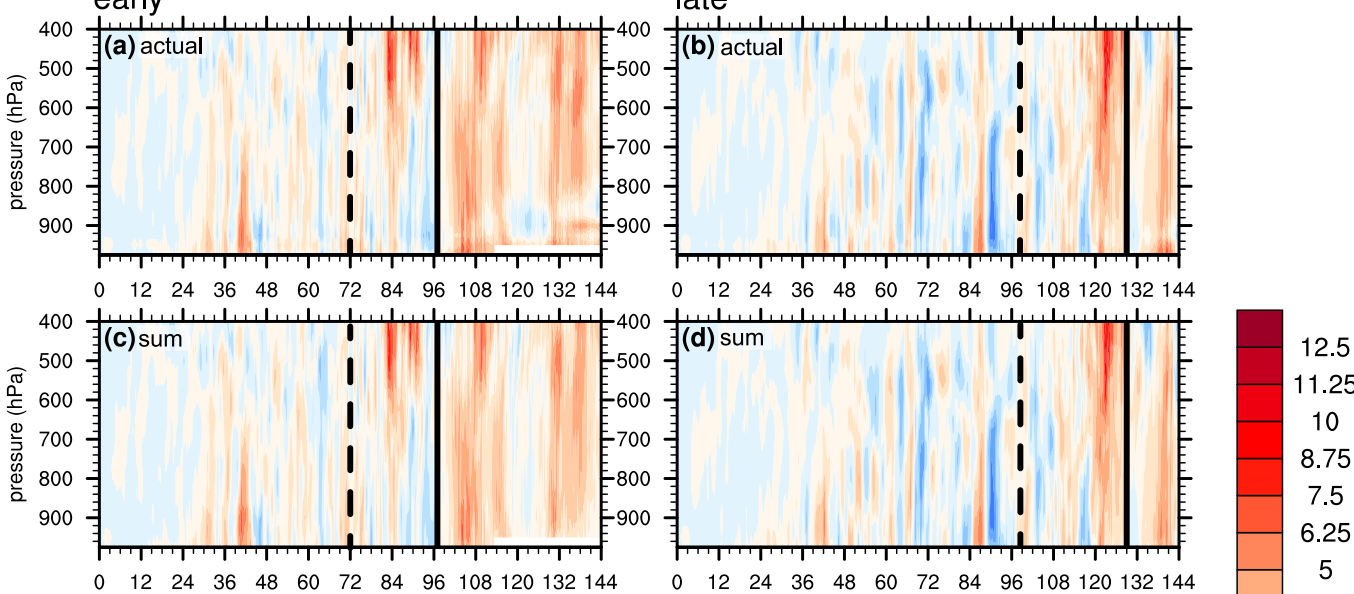

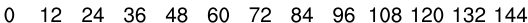
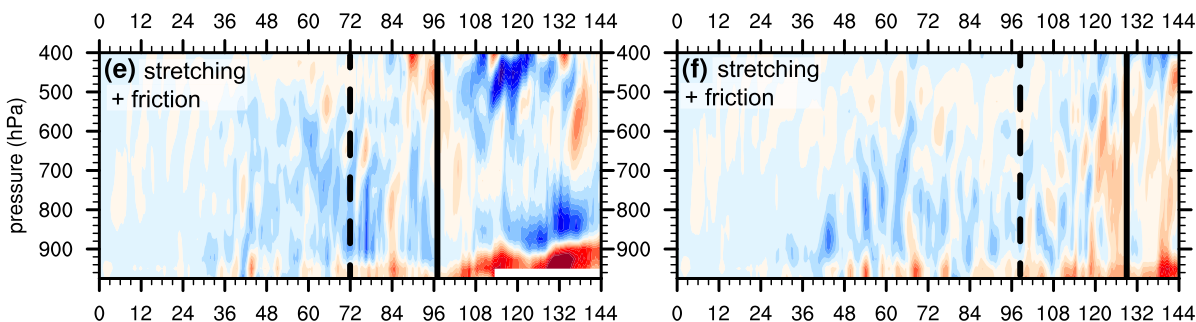

6.25

5

3.75

2.5

1.25

0

$-1.25$

$-2.5$

$-3.75$

$\begin{array}{lllllllllllll}0 & 12 & 24 & 36 & 48 & 60 & 72 & 84 & 96 & 108 & 120 & 132 & 144\end{array}$
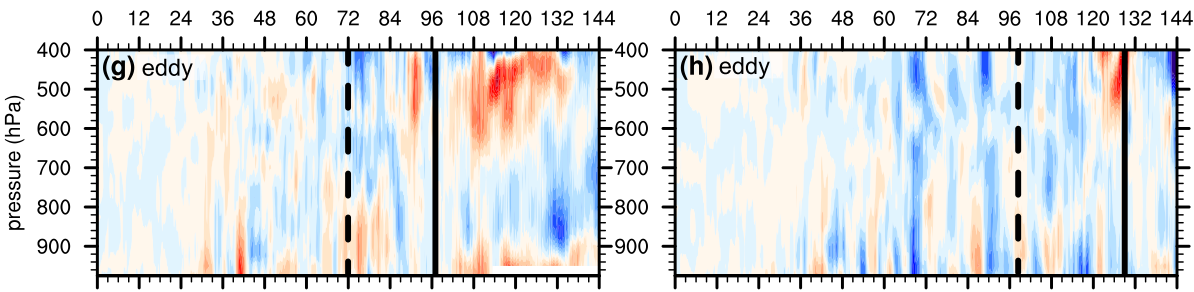

$\begin{array}{lllllllllllll}0 & 12 & 24 & 36 & 48 & 60 & 72 & 84 & 96 & 108 & 120 & 132 & 144\end{array}$
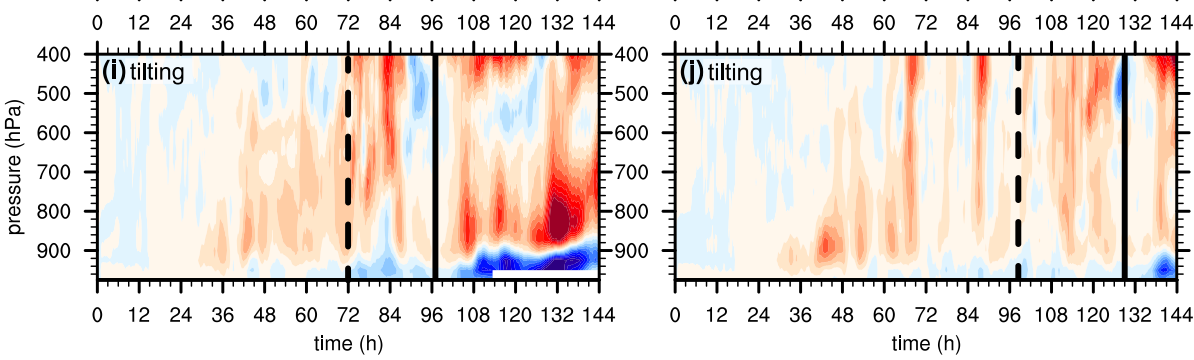

$-5$

$-6.25$

$-7.5$

$-8.75$

$-10$

$-11.25$

$-12.5$

vorticity

change $\left(10^{-5} \mathrm{~s}^{-1} \mathrm{~h}^{-1}\right)$

FIG. 9. As in Fig. 8, but for the tendencies with respect to the lower-tropospheric center of circulation.

Instead, vorticity spins up via tilting of horizontal vorticity above $950 \mathrm{hPa}$ (Figs. 9i,j) and occasional positive eddy fluxes below $800 \mathrm{hPa}$ (Figs. 9g,h). Those tendencies are facilitated by the flow configuration when the midtropospheric vortex is upshear left. Positive tilting mainly happens at the northwestern edges of the integration domain, where upward motion associated with asymmetric convection is collocated with outwardpointing horizontal vorticity induced by the midtropospheric vortex (Fig. 10c). Likewise, positive eddy vorticity fluxes happen near the surface as the stormrelative inflow is collocated with vorticity anomalies generated below the midtropospheric vortex (Fig. 10d).
These results show that tilt reduction is not solely driven by the alignment of lower- and midtropospheric vortices. However, it is unclear which other processes drive tilt reduction after the midtropospheric vortex enters upshear left. This issue was further investigated with a partition of horizontal winds into irrotational $\left(\mathbf{V}_{\chi}\right)$ and nondivergent $\left(\mathbf{V}_{\psi}\right)$ components via a Helmholtz decomposition,

$$
\mathbf{V}_{h}=\mathbf{V}_{\chi}+\mathbf{V}_{\psi}=\nabla_{h} \chi+\hat{\mathbf{z}} \times \nabla_{h} \psi,
$$

where $\chi$ and $\psi$ are a velocity potential and a streamfunction, respectively, that satisfy 

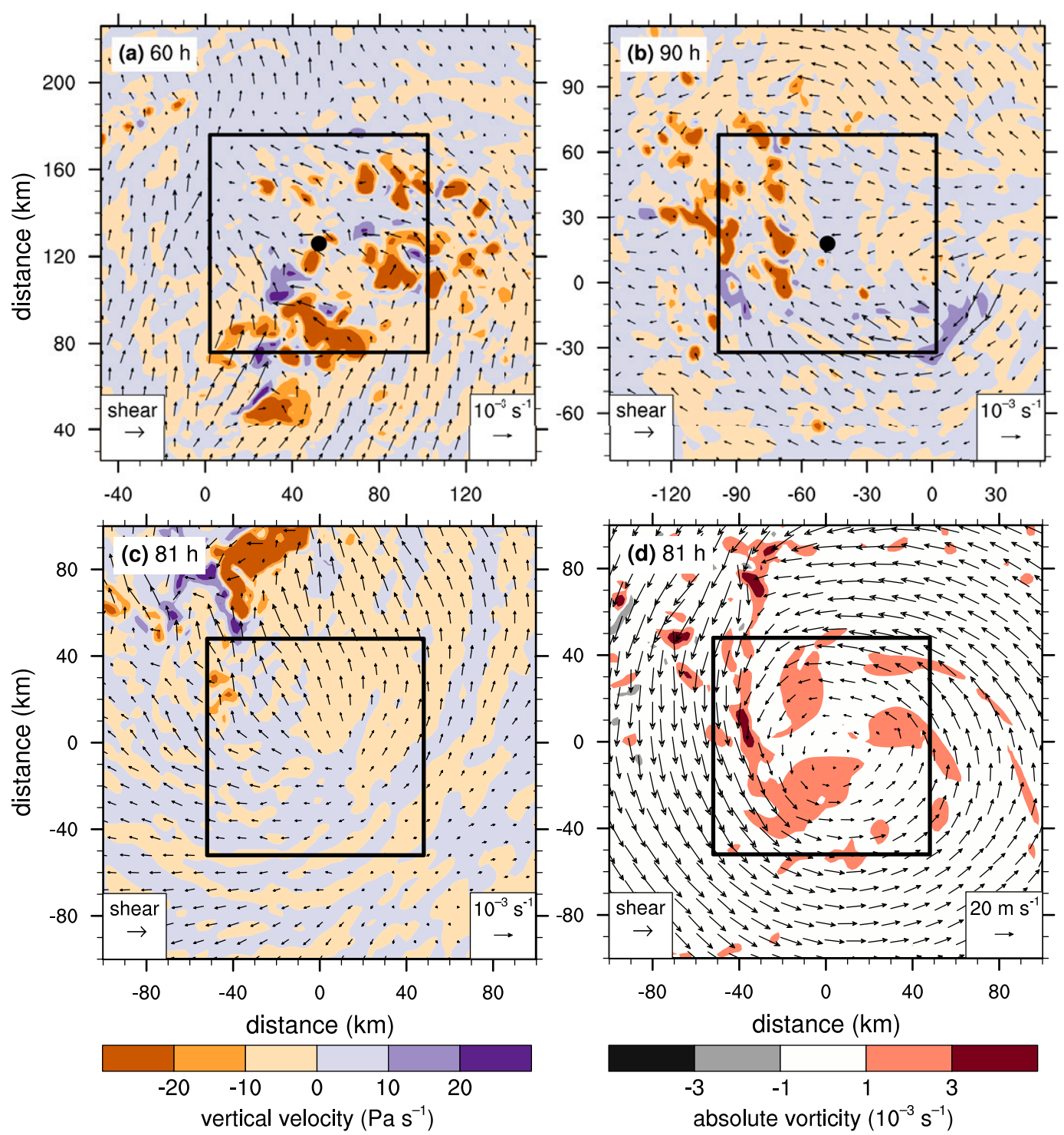

FIG. 10. Horizontal snapshots of 500-700-hPa layer-averaged vertical velocity (shading; every $10 \mathrm{~Pa} \mathrm{~s}^{-1}$ ) and horizontal vorticity (vectors) centered on the $900-\mathrm{hPa}$ center at (a) 60 and (b) $90 \mathrm{~h}$. Black dots indicate the positions of the 400-hPa center. (c) As in (a) and (b), but centered on the 900-hPa center at 81 h. (d) Horizontal snapshot of 950-hPa absolute vorticity (shading; every $0.3 \times 10^{-3} \mathrm{~s}^{-1}$ ) and storm-relative winds (vectors) centered on the $900-\mathrm{hPa}$ center at $81 \mathrm{~h}$. Black boxes depict the vorticity budget integration domain relative to the midtropospheric center in (a) and (b) and the lower-tropospheric center in (c) and (d). Shear direction is indicated at the lower-left corner of each panel. Notice the different domains in (a) and (b).

$$
\nabla^{2} \chi=\nabla \cdot \mathbf{V}_{h}
$$

and

$$
\nabla^{2} \psi=\zeta
$$

Eq. (3) is only valid for periodic domains, which is the case of the outermost domain here. Dirichlet boundary conditions were applied to output from the 2-km domain, assuming that vorticity and divergence vanished outside a $350-\mathrm{km}$ radius from the domain center.
Snapshots of irrotational and nondivergent winds show the contrasting flow configurations when the midtropospheric vortex is downshear left or upshear left. In the former, the surface vortex is broad and composed of multiple mesoscale circulations (Fig. 11a). Updrafts exceeding $1 \mathrm{~m} \mathrm{~s}^{-1}$ happen over a broad region (Fig. 11a), and both convergent and divergent flow appear beneath the midtropospheric vortex (Fig. 11c). In contrast, a single and more compact circulation appears near the surface (Fig. 11b), predominantly convergent flow appears in the vicinity of near-surface vorticity 

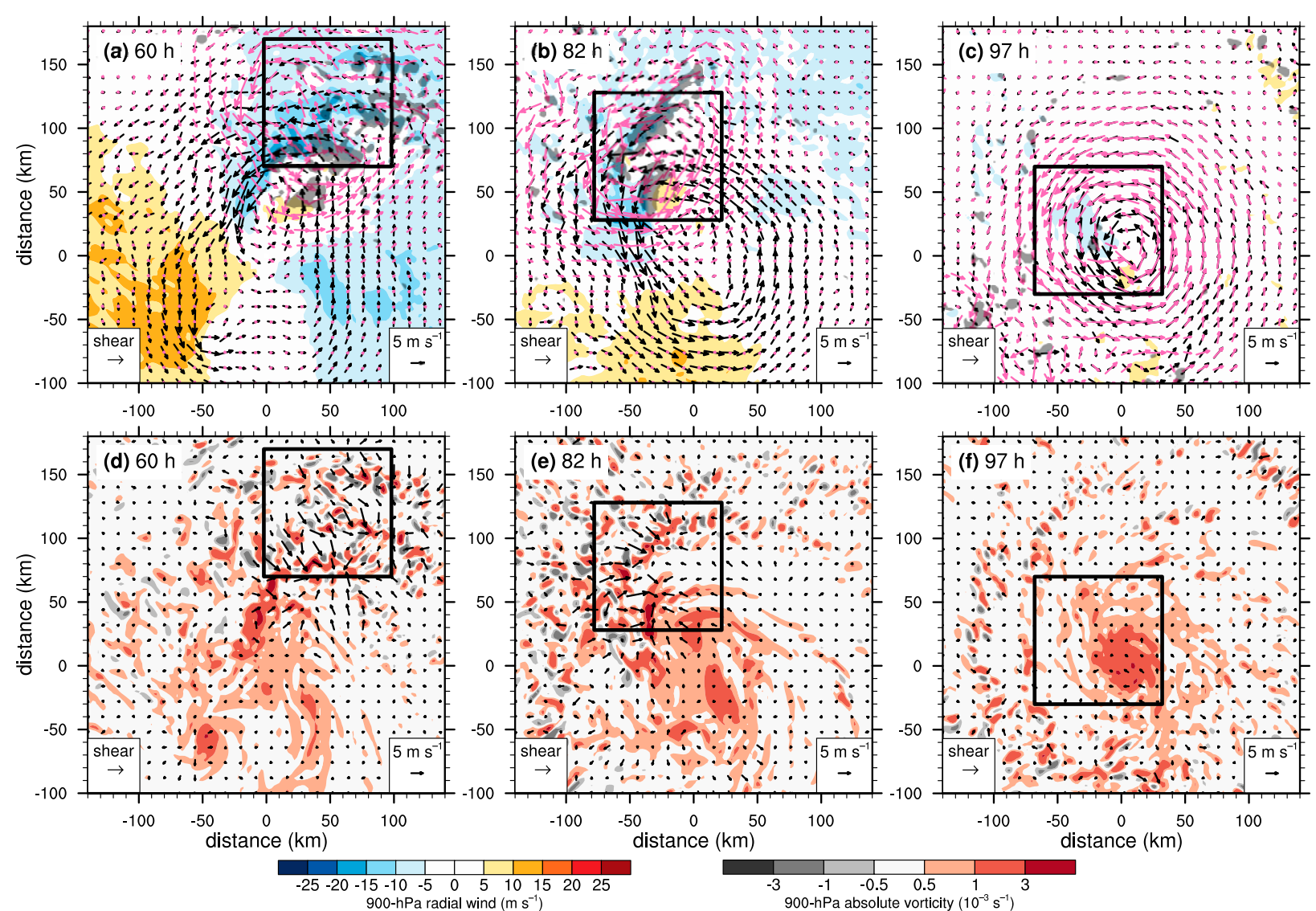

FIG. 11. (a)-(c) Horizontal snapshots of 900-hPa nondivergent winds (black arrows), 400-hPa nondivergent winds (magenta arrows), 900-hPa radial wind (shading; every $5 \mathrm{~m} \mathrm{~s}^{-1}$ ), and 400-900 layer-averaged vertical velocity exceeding $1 \mathrm{~m} \mathrm{~s}^{-1}$ (gray shading) centered on the lower-tropospheric center of the early member at (a) 60, (b) 82, and (c) 97 h. (d)-(f) As in (a)-(c), respectively, but for 900-hPa irrotational winds (black arrows) and absolute vorticity (shading; $10^{-3} \mathrm{~s}^{-1}$ ). Black boxes depict the vorticity budget integration domain following the midtropospheric vortex. Shear direction is indicated at the lower-left corner of each panel.

exceeding $3 \times 10^{-3} \mathrm{~s}^{-1}$ (Fig. 11e), and updrafts exceeding $1 \mathrm{~m} \mathrm{~s}^{-1}$ happen within a region of strong vorticity near the surface and a closed circulation aloft after the midtropospheric vortex enters upshear left (Figs. 11b,e). Although near-surface inflow accompanies the midtropospheric vortex at all times, that inflow is radially closer and near stronger vorticity when the midtropospheric vortex is upshear left.

Together, the irrotational and nondivergent winds point to a vortex merger process on small scales that facilitates tilt reduction. Strong convergence spins up small-scale vortices underneath the midtropospheric vortex, and those vortices coalesce and merge with each other after being advected by the nondivergent winds around a common lower-tropospheric center of circulation and toward each other by the irrotational winds. These processes were directly quantified with the azimuthally averaged eddy radial vorticity flux $\left(-\overline{u^{\prime} \eta^{\prime}}\right)$ averaged within the lowest $1 \mathrm{~km}$; vortex merger happens when this quantity is positive (Hendricks et al. 2004).
Indeed, positive azimuthally averaged eddy fluxes happen inside a 50-km radius from the lower-tropospheric center of both the early and the late members (Fig. 12). All other members also experience a vortex merger, although the timing and intensity varies between members. Distributions of eddy radial vorticity fluxes averaged within 50-km radius and within the lowest $1 \mathrm{~km}$ show large variability, but also show that most members experience vortex merger $12-18 \mathrm{~h}$ before the onset of intensification (Fig. 12c). Merger happens only after the midtropospheric vortex reaches upshear left because that is where the flow configuration favors strong vorticity spinup near the surface and eddy radial fluxes toward a common center of circulation (Figs. 11b,e).

Vortex merger has been recognized as important during tropical cyclogenesis (e.g., Ritchie and Holland 1993; Simpson et al. 1997; Hendricks et al. 2004; Montgomery et al. 2006) and intensification (Van Sang et al. 2008). Recent work on this subject suggests that vortex merger is facilitated by both nondivergent and irrotational vorticity 

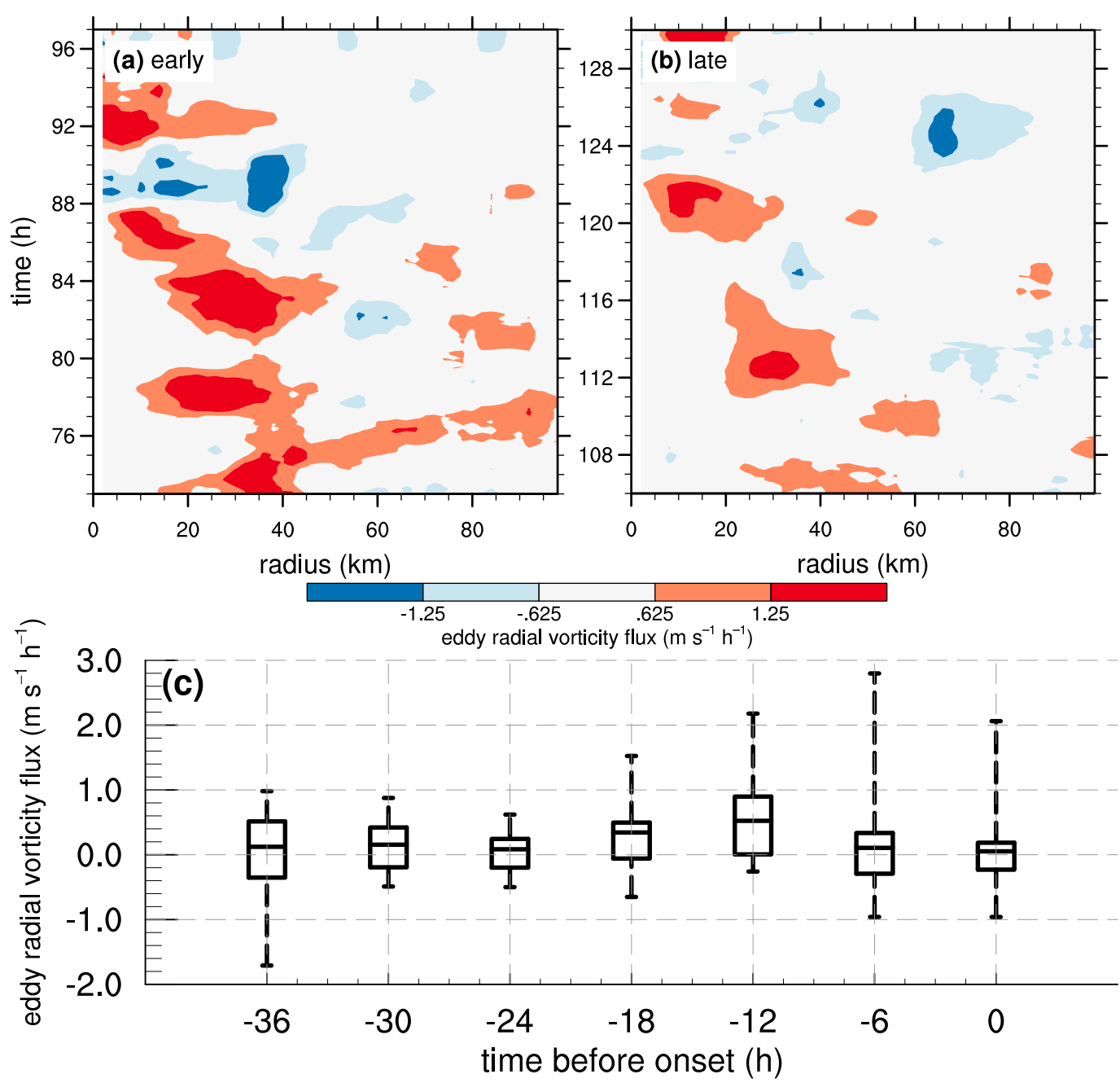

FIG. 12. Time-radius depiction of azimuthally averaged eddy radial vorticity flux (shading; every $0.625 \mathrm{~m} \mathrm{~s}^{-1} \mathrm{~h}^{-1}$ ) averaged below 1-km height of (a) the early and (b) the late members. (c) Ensemble distributions of eddy radial vorticity flux averaged below $1-\mathrm{km}$ height and within a 50-km radius from the lower-tropospheric center of each member. Standard boxplots are used, where whiskers indicate minima and maxima, boxes extend from the 25 th to the 75 th percentiles, and middle lines depict the medians.

fluxes (Schecter 2017). Development of a TC following the merger, however, depends on the distance between the vortices, among other factors (Schecter 2016). Here, vortex merger happened once the midtropospheric vortex moved close enough to the lower-tropospheric vortex to provide an enclosed region of recirculation by the nondivergent flow and coalescence by the irrotational flow. This sequence of events points at an indirect role of shear, where advection by the westerly sheared flow slows down the upshear migration of the midtropospheric vortex, forcing instead a radially inward migration. Following that indirect influence, vortex merger ultimately led to the establishment of a single vertically upright vortex (Figs. 11c,f) accompanied by latent heat release within a closed circulation (Fig. 5d).
These results support a two-stage process as initially proposed by Molinari et al. (2004): 1) a tilted, asymmetric stage and 2) an aligned, symmetric stage. During the first stage, the lower-tropospheric vortex cannot spin up because the convergence of absolute vorticity and latent heat release happen below the midtropospheric vortex, but the midtropospheric vortex cannot build downward because the asymmetric vertical motions are anticorrelated with the horizontal vorticity induced by the main TC vortex. After the midtropospheric vortex and associated precipitation reach upshear left, the flow configuration facilitates vortex stretching and vorticity merger akin to the Van Sang et al. (2008) paradigm. A single vertically aligned vortex emerges and spins up during the second stage via near-surface convergence of 

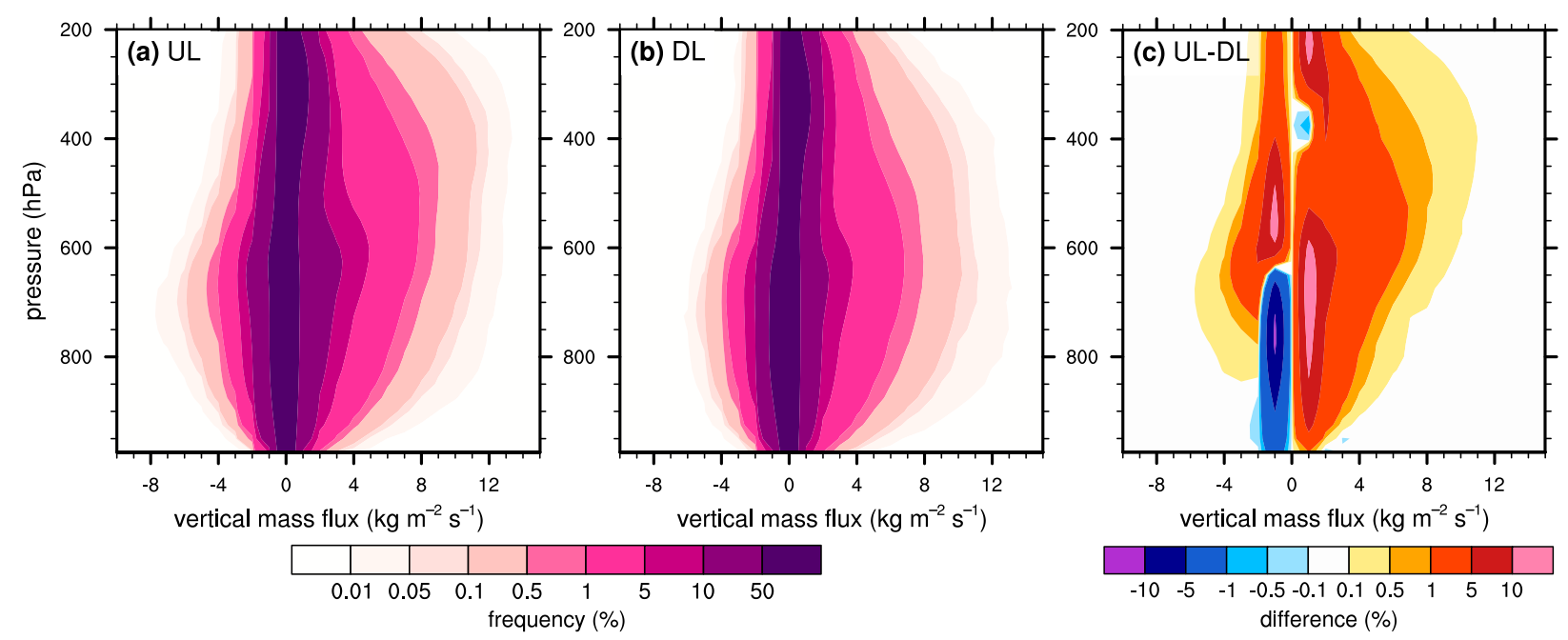

FIG. 13. Ensemble-mean CFADs of vertical mass flux (shading; \% in a semilogarithmic scale) during a 12-h period when the midtropospheric vortex is (a) UL or (b) DL in each member. (c) The differences between (a) and (b).

absolute vorticity, free-tropospheric tilting of horizontal vorticity, and latent heat release within a closed circulation-an evolution that is consistent with axisymmetric theories of intensification (Ooyama 1964, 1969, 1982; Charney and Eliassen 1964; Emanuel 1986).

\section{c. The importance of the upshear-left quadrant}

The previous subsection confirmed the influence of structural changes on the simulated intensification; therefore, it is imperative to explain why those changes happened after the midtropospheric vortex reached upshear left. To understand such changes, the statistics of vertical motions within a $50-\mathrm{km}$ radius from the midtropospheric vortex were assessed via contoured frequency by altitude diagrams (CFADs; Yuter and Houze 1995). CFADs group variables (in this case vertical mass flux) by their values at each height, thus quantifying individual vertical motion contributions to the areaaveraged vertical mass flux profile. CFADs were obtained for each member and averaged during 12-h periods when the midtropospheric vortex was in the upshear-left quadrant (Fig. 13a) or in the downshearleft quadrant (Fig. 13b). Comparing those CFADs shows that the vertical mass flux profile changes because of a reduction of downdrafts below $600 \mathrm{hPa}$ and an increase of updrafts at all levels-especially above $600 \mathrm{hPa}$ - when the midtropospheric vortex reaches upshear left (Fig. 13c). Although it is intriguing that deep updrafts occur more frequently when the midtropospheric vortex reaches a region typically characterized by subsiding air (Reasor et al. 2013; DeHart et al. 2014), real-world intensifying TCs also exhibit strong and deep updrafts in the upshear-left quadrant (Wadler et al. 2018).
This result, which appears in all members, is tied to an increase in deep convective updrafts as depicted by a diagnosis of convective bursts (CBs) within a $50-\mathrm{km}$ radius from the midtropospheric center (Fig. 1c). Convective bursts represent grid points where the 8-16-km layer-averaged vertical velocity exceeded $5 \mathrm{~m} \mathrm{~s}^{-1}$ and the $8-14-\mathrm{km}$ layer-averaged reflectivity exceeded $20 \mathrm{~dB} Z$ (following Rogers et al. 2015 and Judt and Chen 2016). Time series of the number of convective bursts show three key results (Fig. 1c): 1) CBs happen more frequently during the tilted, asymmetric stage than during the aligned, symmetric stage; 2) all members experience a $\mathrm{CB}$ maximum during the 12-24-h period before the onset of intensification; and 3) all members have nearly zero CBs at the onset of intensification.

The first result is consistent with the vertical accelerations induced by a midtropospheric vorticity maximum and its associated thermodynamic structure during the tilted, asymmetric stage but not during the aligned, symmetric stage. The second result is consistent with the evolution of the vertical mass flux profile when the midtropospheric vortex reaches upshear left, further pointing at structural changes that favor deep convective updrafts in that quadrant. Last, the third result shows that the onset of intensification is characterized by a convective minimum, demonstrating that symmetrization (cf. Fig. 1b) results from a large azimuthal coverage of shallow convection and stratiform precipitation (consistent with observations; Tao and Jiang 2015; Tao et al. 2017).

Observations of intensifying TCs have captured upshear-left convective bursts preceding intensification 
(e.g., Stevenson et al. 2014; Rogers et al. 2016; Nguyen et al. 2017; Wadler et al. 2018); however, an explanation for those updrafts is needed. Here, the presence of upshear-left convective bursts was explored with an analysis of air parcel trajectories. Backward trajectories were obtained using the Read/Interpolate/Plot (RIP) software $^{2}$ with 6-min model output interpolated to 1-min frequency. This analysis allows an examination of processes driving vertical accelerations via

$$
\frac{d w}{d t}=g \frac{\theta_{\rho}^{\prime}}{\theta_{\rho}}-\frac{1}{\rho} \frac{\partial p^{\prime}}{\partial z}
$$

where $w$ is vertical velocity, $\theta_{\rho}$ is density potential temperature, $p$ is pressure, $z$ is geometric height, $g$ is the gravitational acceleration, and the overline and prime symbols represent a mean state and a perturbation from that mean state, respectively. One caveat of this analysis is that individual terms depend on the choice of base state. Following the analysis of Braun (2002) and recommendations of Smith et al. (2005), the base state was defined as the sum of wavenumbers 0 and 1 at each radius and height. The first term on the right-hand side of Eq. (4) represents buoyant accelerations, whereas the second term represents dynamic accelerations due to nonhydrostatic pressure gradient forces. This analysis is not meant to be exact because of the temporal resolution of model output and lack of output to account for diffusion, but it provides a general estimate of different forcings for ascent. Contributions from each term were obtained for air parcels originating at grid points with a vertical velocity exceeding $5 \mathrm{~m} \mathrm{~s}^{-1}$ at $300 \mathrm{hPa}$ (approximately $10 \mathrm{~km}$ ) at the time of maximum convective bursts in the early (82 h) and the late member (117 h).

Parcel trajectories examined during the convective bursts maximum demonstrate that both buoyant and dynamic accelerations promote deep convective updrafts in the upshear-left quadrant. Figure 14 shows this result through a pressure-azimuth depiction of the buoyant and dynamic acceleration along parcel trajectories only after the parcels had started ascending. Air parcels begin ascending in the region azimuthally upwind of the midtropospheric vortex. Most air parcels become positively buoyant after they begin ascending above $500 \mathrm{hPa}$ (Figs. 14a,b). Such buoyant accelerations are likely aided by latent heat release as warm and moist air parcels rise at a small radius relative to the lowertropospheric center. At the same time, air parcels experience dynamic accelerations through their entire

\footnotetext{
${ }^{2} \mathrm{RIP}$ is freely available (http://www2.mmm.ucar.edu/wrf/users/ docs/ripug.htm).
}

ascending trajectories (Figs. 14c,d). This dynamic forcing for ascent represents an upward-directed nonhydrostatic pressure gradient force associated with the stronger vorticity aloft (Figs. 5c, 11b). The presence of the midtropospheric vortex, and its associated low pressure away from the surface, provides a dynamic forcing for ascent.

Another mechanism contributing to the shift in the vertical mass flux profile is a reduction of downward fluxes of low-entropy air. As was illustrated in Fig. 13, downdraft activity substantially decreases after the midtropospheric vortex enters upshear left. The reason for such reduction was examined with backward trajectories of air parcels that ended near the surface within a $50-\mathrm{km}$ radius from the midtropospheric center of the early member. Before the midtropospheric vortex reaches upshear left, many air parcels originate near the $\theta_{e}$ minimum (cf. Fig. 7) and descend within a mesoscale downdraft below and azimuthally downwind of the midtropospheric vortex (Fig. 15a). By contrast, most air parcels are recirculated and maintain a warm, moist boundary layer following the arrival of the midtropospheric vortex to upshear left (Fig. 15b). Those contrasting trajectories happen because the lowertropospheric vortex remains a reservoir of high- $\theta_{e}$ air due to continued surface moisture fluxes, and air parcels with high $\theta_{e}$ can only enter the midtropospheric vortex when it moves radially close to the lowertropospheric vortex.

All members exhibit this reduction of downward lowentropy fluxes (DFX), which was quantified via

$$
\mathrm{DFX}=w_{-} \theta_{e}^{\prime},
$$

where $w_{-}$represents downward motion and the prime symbol denotes departure from the azimuthal mean (Riemer et al. 2010). Figure 15c shows ensemble distributions of DFX averaged within a $50-\mathrm{km}$ center of the midtropospheric center and below $900 \mathrm{hPa}$. Evidently, low-entropy fluxes decrease in all members during the $24 \mathrm{~h}$ preceding intensification. Recirculating air parcels promote increasing $\theta_{e}$ below $600 \mathrm{hPa}$ (Fig. 7) and near saturation that favors ascent via buoyant accelerations (Figs. 14a,b).

This analysis provides an explanation for the appearance and impact of upshear-left convective updrafts preceding intensification. Deep updrafts happen within a closed circulation, where the stronger vorticity aloft induces an upward acceleration. The associated strong ascent within the closed region aids lower-tropospheric moistening by suppressing downdrafts, reducing lowentropy downward fluxes, and promoting recirculating warm, moist air parcels. Recirculation happens within 

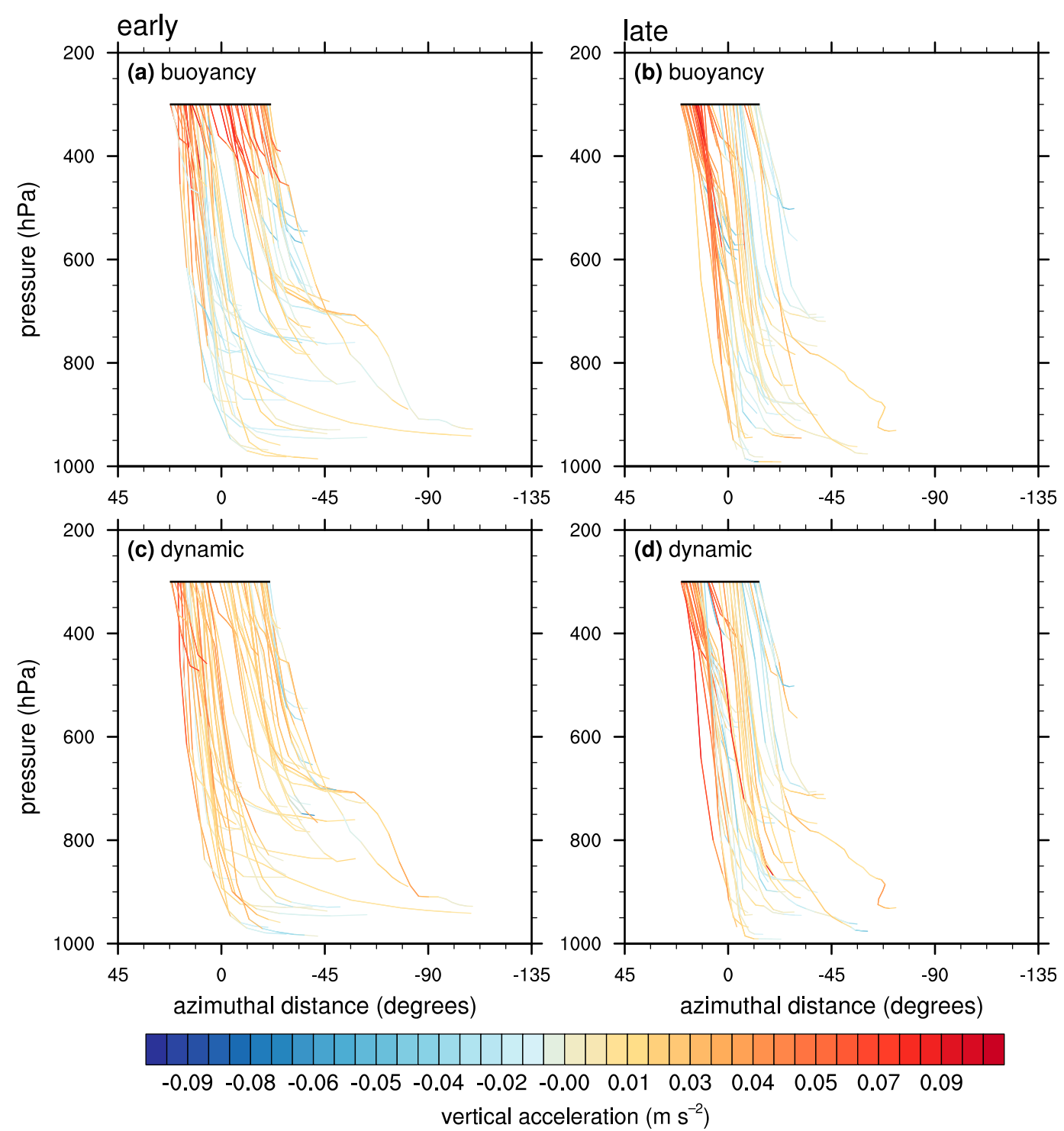

FIG. 14. Pressure-azimuth depiction of backward trajectories released from $300 \mathrm{hPa}$ at (a),(c) $82 \mathrm{~h}$ of the early member and (b),(d) $117 \mathrm{~h}$ of the late member for (a),(b) buoyant and (c),(d) dynamic accelerations (shading; every $0.025 \mathrm{~m} \mathrm{~s}^{-1}$ ) along the trajectories only during parcel ascent. Black lines indicate the location from where parcels were released. Distance is given relative to the midtropospheric center, where negative (positive) values represent azimuthally upwind (downwind) distance.

an enclosed region where the nondivergent winds are much stronger than the irrotational winds (Figs. 11c,f), thus inhibiting cool, dry air intrusions from the environment (Raymond and López Carrillo 2011). The late member experiences those processes much later because of more downdrafts (Fig. 7), fewer convective bursts (Fig. 1c), and larger downshear-left tilt (Fig. 3a). Following vortex merger initiated by the deep updrafts and associated vortex stretching, the reformed surfacebased vortex has favorable kinematic and thermodynamic conditions to undergo intensification.

\section{Summary, hypothesis, and open questions}

An ensemble of idealized numerical simulations was used to diagnose physical processes preceding TC intensification under moderate VWS. Consistent with previous studies, the ensemble was characterized by large variability in the simulated intensity, precipitation asymmetry, and vortex tilt. New insights were gained through a process-based analysis centered on the characteristics and evolution of a shear-induced midtropospheric vortex. This analysis showed that intensification 

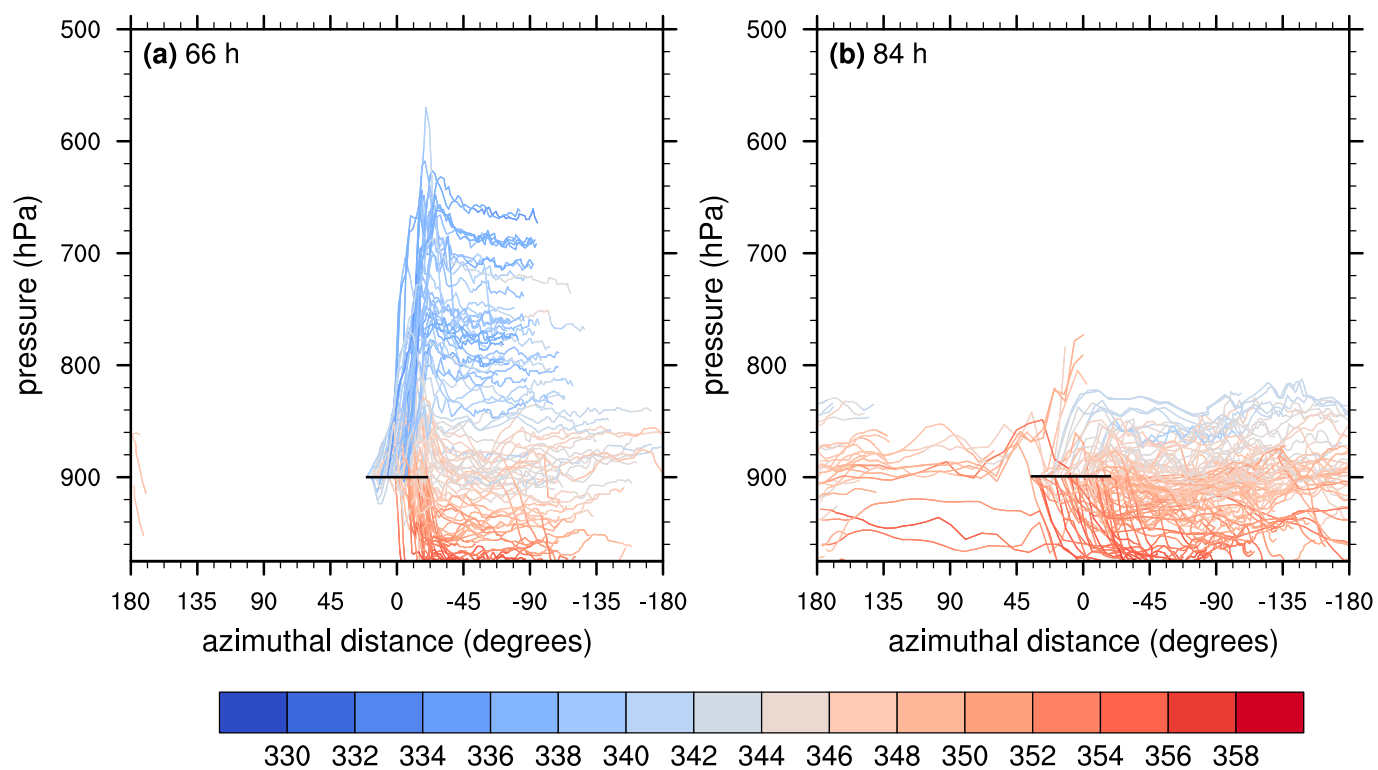

equivalent potential temperature $(\mathrm{K})$

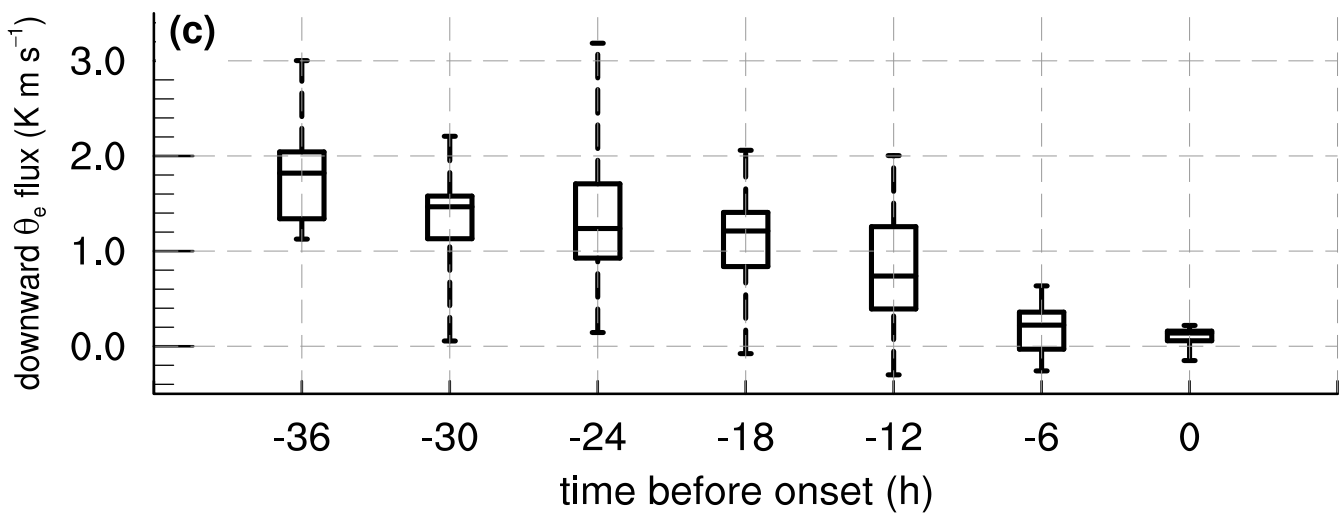

FIG. 15. Pressure-azimuth depiction of backward trajectories released from $900 \mathrm{hPa}$ and within a 50-km radius from the midtropospheric vortex of the early member. Colors depict equivalent potential temperature (shading; every $2 \mathrm{~K}$ ) for parcels released backward at (a) 66 and (b) 84 h. (c) Ensemble distributions of downward entropy fluxes averaged below $900 \mathrm{hPa}$ and within a 50-km radius from the midtropospheric center. Standard boxplots are used, where whiskers show the minima and maxima, boxes extend from the 25th to the 75th percentiles, and middle lines depict the medians.

followed after tilt reduction and symmetrization of precipitation because that structure promoted persistent vorticity spinup and recirculating warm, moist air parcels. All members exhibited similar processes driving intensification; however, the timing of intensification varied between members because of their initial downshear-left tilt magnitude and subsequent timing of tilt reduction.

The sequence of events in these idealized simulations can be summarized as follows:

- A mesoscale midtropospheric vortex emerges within the shear-organized precipitation.

- The midtropospheric vortex travels cyclonically around a lower-tropospheric center of circulation at a distance that depends on the precise location of shear-organized convection.

- Upon reaching upshear left, shear slows down the upshear migration of the vortex and forces instead a radially inward migration.

- Deep convective updrafts emerge and spin up strong, small-scale vortices that coalesce and merge into a single closed circulation over a deep layer.

- Vortex merger happens only after the midtropospheric vortex reaches upshear left, where the flow configuration favors near-surface vortex stretching and eddy radial vorticity fluxes toward a common center of circulation. 
- Recirculating air parcels prevent downdrafts and allow for a warming and moistening lower troposphere within the closed circulation.

- Last, the vertically aligned TC intensifies via nearsurface convergence of absolute vorticity, tilting of horizontal vorticity, and latent heat release within the closed circulation.

Based on these results, it is hypothesized that intensification under moderate VWS happens if and when a two-stage "restructuring" process takes place. During the first stage, precipitation is asymmetric because rising motions happen predominantly near the midtropospheric vortex, the combination of elevated deep convection and stratiform precipitation yield a top-heavy vertical mass flux profile, and strong downdrafts bring low-entropy air to the boundary layer. This structure changes during the second stage when vortex merger leads to a single closed circulation over a deep layer, vertical mass fluxes increase near the surface, and highentropy air persists in the boundary layer. Intensification proceeds during the second stage with only minor effects from VWS because precipitation is nearly symmetric and the TC vortex remains nearly aligned. A restructuring process is proposed based on those system-scale structural changes. This hypothesis is similar to the two-stage process proposed by Molinari et al. (2004), except with the added vortex merger paradigm proposed by Van Sang et al. (2008).

It is further hypothesized that the likelihood and length of that restructuring process depend on environmental and internal conditions, in agreement with other studies of TC intensification under moderate VWS (Tao and Zhang 2014; Rios-Berrios and Torn 2017; Nguyen et al. 2017). Sheared TCs within favorable environmental thermodynamics (e.g., abundant moisture, warm sea surface temperature) are more likely to complete the restructuring process because of continuous support for ascent and inhibition of downdrafts (e.g., Tao and Zhang 2014; Nguyen et al. 2017). Environmental conditions ahead of the midtropospheric vortex and in the upshear half are especially important to ensure the sustainment and propagation of precipitation from downshear left to upshear left (Rappin and Nolan 2012; Ge et al. 2013; Onderlinde and Nolan 2016; RiosBerrios et al. 2016b,a; Rios-Berrios and Torn 2017). Likewise, the restructuring process likely applies to weak TCs-depressions, tropical storms, and weak hurricaneswhich are more likely to exhibit a tilted, asymmetric structure than strong, mature TCs (Jones 1995; DeMaria 1996; Reasor et al. 2004; Riemer and Montgomery 2011). Further investigation is needed to confirm these hypotheses and to establish how shear-related processes such as ventilation affect the hypothesized restructuring process.

Although idealized, these simulations are consistent with intensification of real-world TCs. Humidification of the upshear half and symmetrization of precipitation are key characteristics of intensifying TCs under moderate VWS (Molinari et al. 2004; Kieper and Jiang 2012; Jiang and Ramirez 2013; Zagrodnik and Jiang 2014; RiosBerrios et al. 2016a; Zawislak et al. 2016; Nguyen et al. 2017; Rios-Berrios and Torn 2017). Symmetrization is often preceded by upshear-left convective bursts (e.g., Rogers 2010; Stevenson et al. 2014; Chen and Gopalakrishnan 2015; Rogers et al. 2016; Wadler et al. 2018), even though upshear-left bursts do not always lead to intensification (Judt and Chen 2016). New insights were gained here about the origin and relevance of those convective bursts: dynamic forcing for ascent appeared below the midtropospheric vorticity maximum, and that ascent promoted increasing near-surface vertical mass fluxes and humidification of the lower and midtroposphere. Observations of upshear-left convective bursts during the intensification of Hurricane Earl (2010) support this result, as those bursts also happened near a midtropospheric vorticity maximum (Stevenson et al. 2014). Tilt reduction is also a common feature of observed intensifying TCs in sheared environments (e.g., Raymond and López Carrillo 2011; Reasor and Eastin 2012; Rogers et al. 2015). Importantly, tilt reduction happened through stretching, tilting, and vortex merger-not solely through advective vortex alignment.

Several questions remain open for future research. For example, what mechanisms inhibit the hypothesized restructuring process? This study focused on intensification, but an equally important problem is TC weakening under moderate or strong VWS. One possibility is that the restructuring process is inhibited by processes that prevent vortex merger and the subsequent establishment of a single closed circulation. Likewise, can the vortex merger process happen in other quadrants? Some TCs intensify after vortex reformation in the downshear half (Molinari et al. 2004, 2006; Davis et al. 2008; Molinari and Vollaro 2010; Nguyen and Molinari 2015); therefore, vortex merger and reformation may depend on other factors such as the flow configuration, thermodynamic background, or the distance between the deep updrafts and a lower-tropospheric center of circulation. Another question that remains unanswered is, What factors control the azimuthal motion of the midtropospheric vortex and its associated precipitation? The onset of intensification largely depends on that motion (cf. Fig. 3), but the ensemble was characterized by large variability induced by small perturbations to the initial boundary layer 
water vapor. These and other questions should be addressed, especially with observations and with simulations that account for temporal shear variability, to further understand the hypothesized restructuring process.

Acknowledgments. This study would not have been possible without the point downscaling code provided by Drs. David Nolan and Matthew Onderlinde. Comments from three anonymous reviewers helped improve an earlier version of this manuscript. This study also benefited from discussions with Drs. George Bryan, Kristen Corbosiero, John Molinari, and Brian Tang. Dr. Jimy Dudhia, Dr. Wei Wang, and Ms. Kelly Werner from NCAR helped in numerous ways with the modeling experiments. All experiments were performed with an educational allocation in the Yellowstone Supercomputer System administered by NCAR's Computational Information Systems Laboratory (CISL; CISL 2012) during the first author's visit to NCAR, sponsored by NCAR's Advanced Study Program Graduate Visitor fellowship. This research also funded through NOAA Grants NA14OAR4830172 and NA16NWS4680025. The National Center for Atmospheric Research is sponsored by the National Science Foundation.

\section{REFERENCES}

Alland, J. J., B. H. Tang, and K. L. Corbosiero, 2017: Effects of midlevel dry air on development of the axisymmetric tropical cyclone secondary circulation. J. Atmos. Sci., 74, 1455-1470, https://doi.org/10.1175/JAS-D-16-0271.1.

Bhatia, K. T., and D. S. Nolan, 2013: Relating the skill of tropical cyclone intensity forecasts to the synoptic environment. Wea. Forecasting, 28, 961-980, https://doi.org/10.1175/WAF-D-1200110.1.

Braun, S. A., 2002: A cloud-resolving simulation of Hurricane Bob (1991): Storm structure and eyewall buoyancy. Mon. Wea. Rev., 130, 1573-1592, https://doi.org/10.1175/1520-0493(2002) $130<1573$ :ACRSOH $>2.0 . \mathrm{CO} ; 2$.

Charney, J. G., and A. Eliassen, 1964: On the growth of the hurricane depression. J. Atmos. Sci., 21, 68-75, https://doi.org/ 10.1175/1520-0469(1964)021<0068:OTGOTH >2.0.CO;2.

Chen, H., and S. G. Gopalakrishnan, 2015: A study on the asymmetric rapid intensification of Hurricane Earl (2010) using the HWRF system. J. Atmos. Sci., 72, 531-550, https://doi.org/ 10.1175/JAS-D-14-0097.1.

Chen, S. S., J. A. Knaff, and F. D. Marks Jr., 2006: Effects of vertical wind shear and storm motion on tropical cyclone rainfall asymmetries deduced from TRMM. Mon. Wea. Rev., 134, 3190-3208, https://doi.org/10.1175/MWR3245.1.

CISL, 2012: Yellowstone: IBM iDataPlex System (University Community Computing). National Center for Atmospheric Research, http://n2t.net/ark:/85065/d7wd3xhc.

Corbosiero, K. L., and J. Molinari, 2002: The effects of vertical wind shear on the distribution of convection in tropical cyclones. Mon. Wea. Rev., 130, 2110-2123, https://doi.org/10.1175/15200493(2002)130<2110:TEOVWS > 2.0.CO;2.
Davis, C. A., 2015: The formation of moist vortices and tropical cyclones in idealized simulations. J. Atmos. Sci., 72, 34993516, https://doi.org/10.1175/JAS-D-15-0027.1.

— , and T. J. Galarneau Jr., 2009: The vertical structure of mesoscale convective vortices. J. Atmos. Sci., 66, 686-704, https:// doi.org/10.1175/2008JAS2819.1.

_ B. Brown, and R. Bullock, 2006: Object-based verification of precipitation forecasts. Part I: Methodology and application to mesoscale rain areas. Mon. Wea. Rev., 134, 1772-1784, https:// doi.org/10.1175/MWR3145.1.

_ S. C. Jones, and M. Riemer, 2008: Hurricane vortex dynamics during Atlantic extratropical transition. J. Atmos. Sci., 65, 714-736, https://doi.org/10.1175/2007JAS2488.1.

DeHart, J. C., R. A. Houze Jr., and R. F. Rogers, 2014: Quadrant distribution of tropical cyclone inner-core kinematics in relation to environmental shear. J. Atmos. Sci., 71, 2713-2732, https://doi.org/10.1175/JAS-D-13-0298.1.

DeMaria, M., 1996: The effect of vertical shear on tropical cyclone intensity change. J. Atmos. Sci., 53, 2076-2088, https://doi.org/ 10.1175/1520-0469(1996)053<2076:TEOVSO > 2.0.CO;2.

_ diction Scheme (SHIPS) for the Atlantic basin. Wea. Forecasting, 9, 209-220, https://doi.org/10.1175/1520-0434(1994) 009<0209:ASHIPS > 2.0.CO;2.

Dunion, J. P., 2011: Rewriting the climatology of the tropical North Atlantic and Caribbean Sea atmosphere. J. Climate, 24, 893-908, https://doi.org/10.1175/2010JCLI3496.1.

Elsberry, R. L., and M.-S. Park, 2017: Comments on "Multiscale structure and evolution of Hurricane Earl (2010) during rapid intensification." Mon. Wea. Rev., 145, 1565-1571, https:// doi.org/10.1175/MWR-D-16-0301.1.

Emanuel, K. A., 1986: An air-sea interaction theory for tropical cyclones. Part I: Steady-state maintenance. J. Atmos. Sci., $\mathbf{4 3}$, 585-605, https://doi.org/10.1175/1520-0469(1986)043<0585: AASITF $>2.0 . \mathrm{CO} ; 2$.

Finocchio, P. M., and S. J. Majumdar, 2017: The predictability of idealized tropical cyclones in environments with time-varying vertical wind shear. J. Adv. Model. Earth Syst., 9, 2836-2862, https://doi.org/10.1002/2017MS001168.

,-- D. S. Nolan, and M. Iskandarani, 2016: Idealized tropical cyclone responses to the height and depth of environmental vertical wind shear. Mon. Wea. Rev., 144, 21552175, https://doi.org/10.1175/MWR-D-15-0320.1.

Foerster, A. M., M. M. Bell, P. A. Harr, and S. C. Jones, 2014: Observations of the eyewall structure of Typhoon Sinlaku (2008) during the transformation stage of extratropical transition. Mon. Wea. Rev., 142, 3372-3392, https://doi.org/10.1175/ MWR-D-13-00313.1.

Ge, X., T. Li, and M. Peng, 2013: Effects of vertical shears and midlevel dry air on tropical cyclone developments. J. Atmos. Sci., 70, 3859-3875, https://doi.org/10.1175/JAS-D-13-066.1.

Gjorgjievska, S., and D. J. Raymond, 2014: Interaction between dynamics and thermodynamics during tropical cyclogenesis. Atmos. Chem. Phys., 14, 3065-3082, https://doi.org/10.5194/ acp-14-3065-2014.

Hence, D. A., and R. A. Houze Jr., 2011: Vertical structure of hurricane eyewalls as seen by the TRMM precipitation radar. J. Atmos. Sci., 68, 1637-1652, https://doi.org/10.1175/ 2011JAS3578.1.

Hendricks, E. A., M. T. Montgomery, and C. A. Davis, 2004: The role of "vortical" hot towers in the formation of Tropical Cyclone Diana (1984). J. Atmos. Sci., 61, 1209-1232, https:// doi.org/10.1175/1520-0469(2004)061<1209:TROVHT>2.0.CO;2. 
_- M. S. Peng, B. Fu, and T. Li, 2010: Quantifying environmental control on tropical cyclone intensity change. Mon. Wea. Rev., 138, 3243-3271, https://doi.org/10.1175/2010MWR3185.1.

Hong, S.-Y., J. Dudhia, and S.-H. Chen, 2004: A revised approach to ice microphysical processes for the bulk parameterization of clouds and precipitation. Mon. Wea. Rev., 132, 103-120, https://doi.org/10.1175/1520-0493(2004)132<0103:ARATIM> 2.0.CO;2.

—_, Y. Noh, and J. Dudhia, 2006: A new vertical diffusion package with an explicit treatment of entrainment processes. Mon. Wea. Rev., 134, 2318-2341, https://doi.org/ 10.1175/MWR3199.1.

Houze, R. A., Jr., 2004: Mesoscale convective systems. Rev. Geophys., 42, RG4003, https://doi.org/10.1029/2004RG000150.

Jiang, H., and E. M. Ramirez, 2013: Necessary conditions for tropical cyclone rapid intensification as derived from 11 years of TRMM data. J. Climate, 26, 6459-6470, https://doi.org/ 10.1175/JCLI-D-12-00432.1.

Jones, S. C., 1995: The evolution of vortices in vertical shear. I: Initially barotropic vortices. Quart. J. Roy. Meteor., 121, 821-851, https://doi.org/10.1002/qj.49712152406.

Judt, F., and S. S. Chen, 2016: Predictability and dynamics of tropical cyclone rapid intensification deduced from highresolution stochastic ensembles. Mon. Wea. Rev., 144, 4395-4420, https://doi.org/10.1175/MWR-D-15-0413.1.

Kieper, M. E., and H. Jiang, 2012: Predicting tropical cyclone rapid intensification using the $37 \mathrm{GHz}$ ring pattern identified from passive microwave measurements. Geophys. Res. Lett., 39, L13804, https://doi.org/10.1029/2012GL052115.

Leighton, H., S. Gopalakrishnan, J. A. Zhang, R. F. Rogers, Z. Zhang, and V. Tallapragada, 2018: Azimuthal distribution of deep convection, environmental factors, and tropical cyclone rapid intensification: A perspective from HWRF ensemble forecasts of Hurricane Edouard (2014). J. Atmos. Sci., 75, 275-295, https://doi.org/10.1175/JAS-D-17-0171.1.

Merrill, R. T., 1988: Environmental influences on hurricane intensification. J. Atmos. Sci., 45, 1678-1687, https://doi.org/ 10.1175/1520-0469(1988)045<1678:EIOHI>2.0.CO;2.

Miyamoto, Y., and D. S. Nolan, 2018: Structural changes preceding rapid intensification in tropical cyclones as shown in a large ensemble of idealized simulations. J. Atmos. Sci., 75, 555-569, https://doi.org/10.1175/JAS-D-17-0177.1.

Molinari, J., and D. Vollaro, 2010: Rapid intensification of a sheared tropical storm. Mon. Wea. Rev., 138, 3869-3885, https://doi.org/ 10.1175/2010MWR3378.1.

- — — , and K. L. Corbosiero, 2004: Tropical cyclone formation in a sheared environment: A case study. J. Atmos. Sci., 61, 2493-2509, https://doi.org/10.1175/JAS3291.1.

— - P. Dodge, D. Vollaro, K. L. Corbosiero, and F. Marks Jr., 2006: Mesoscale aspects of the downshear reformation of a tropical cyclone. J. Atmos. Sci., 63, 341-354, https://doi.org/ 10.1175/JAS3591.1.

— J. J. Frank, and D. Vollaro, 2013: Convective bursts, downdraft cooling, and boundary layer recovery in a sheared tropical storm. Mon. Wea. Rev., 141, 1048-1060, https://doi.org/10.1175/ MWR-D-12-00135.1.

Montgomery, M. T., M. E. Nicholls, T. A. Cram, and A. B. Saunders, 2006: A vortical hot tower route to tropical cyclogenesis. J. Atmos. Sci., 63, 355-386, https://doi.org/10.1175/JAS3604.1.

- L. L. Lussier III, R. W. Moore, and Z. Wang, 2010: The genesis of Typhoon Nuri as observed during the Tropical Cyclone Structure 2008 (TCS-08) field experiment-Part 1:
The role of the easterly wave critical layer. Atmos. Chem. Phys., 10, 9879-9900, https://doi.org/10.5194/acp-10-9879-2010.

Munsell, E. B., F. Zhang, J. A. Sippel, S. A. Braun, and Y. Weng, 2017: Dynamics and predictability of the intensification of Hurricane Edouard (2014). J. Atmos. Sci., 74, 573-595, https:// doi.org/10.1175/JAS-D-16-0018.1.

Nguyen, L. T., and J. Molinari, 2015: Simulation of the downshear reformation of a tropical cyclone. J. Atmos. Sci., 72, 45294551, https://doi.org/10.1175/JAS-D-15-0036.1.

,-- , and D. Thomas, 2014: Evaluation of tropical cyclone center identification methods in numerical models. Mon. Wea. Rev., 142, 4326-4339, https://doi.org/10.1175/MWR-D-14-00044.1.

— R. F. Rogers, and P. D. Reasor, 2017: Thermodynamic and kinematic influences on precipitation symmetry in sheared tropical cyclones: Bertha and Cristobal (2014). Mon. Wea. Rev., 145, 4423-4446, https://doi.org/10.1175/MWR-D-17-0073.1.

Nolan, D. S., 2011: Evaluating environmental favorableness for tropical cyclone development with the method of pointdownscaling. J. Adv. Model. Earth Syst., 3, M08001, https:// doi.org/10.1029/2011MS000063.

Onderlinde, M. J., and D. S. Nolan, 2014: Environmental helicity and its effects on development and intensification of tropical cyclones. J. Atmos. Sci., 71, 4308-4320, https://doi.org/10.1175/ JAS-D-14-0085.1.

$\longrightarrow$, and —, 2016: Tropical cyclone-relative environmental helicity and the pathways to intensification in shear. J. Atmos. Sci., 73, 869-890, https://doi.org/10.1175/JAS-D-15-0261.1.

Ooyama, K., 1964: A dynamical model for the study of tropical cyclone development. Geophys. Int., 4, 187-198.

- 1969: Numerical simulation of the life cycle of tropical cyclones. J. Atmos. Sci., 26, 3-40, https://doi.org/10.1175/15200469(1969)026<0003:NSOTLC $>2.0$.CO;2.

- 1982: Conceptual evolution of the theory and modeling of the tropical cyclone. J. Meteor. Soc. Japan, 60, 369-379, https:// doi.org/10.2151/jmsj1965.60.1_369.

Paterson, L. A., B. N. Hanstrum, N. E. Davidson, and H. C. Weber, 2005: Influence of environmental vertical wind shear on the intensity of hurricane-strength tropical cyclones in the Australian region. Mon. Wea. Rev., 133, 3644-3660, https://doi.org/ 10.1175/MWR3041.1.

Rappin, E. D., and D. S. Nolan, 2012: The effect of vertical shear orientation on tropical cyclogenesis. Quart. J. Roy. Meteor. Soc., 138, 1035-1054, https://doi.org/10.1002/qj.977.

Raymond, D. J., 1992: Nonlinear balance and potential-vorticity thinking at large Rossby number. Quart. J. Roy. Meteor. Soc., 118, 987-1015, https://doi.org/10.1002/qj.49711850708.

, and S. L. Sessions, 2007: Evolution of convection during tropical cyclogenesis. Geophys. Res. Lett., 34, L06811, https:// doi.org/10.1029/2006GL028607.

, and C. López Carrillo, 2011: The vorticity budget of developing Typhoon Nuri (2008). Atmos. Chem. Phys., 11, 147-163, https://doi.org/10.5194/acp-11-147-2011.

Reasor, P. D., and M. D. Eastin, 2012: Rapidly intensifying Hurricane Guillermo (1997). Part II: Resilience in shear. Mon. Wea. Rev., 140, 425-444, https://doi.org/10.1175/MWR-D-11-00080.1.

— , and M. T. Montgomery, 2015: Evaluation of a heuristic model for tropical cyclone resilience. J. Atmos. Sci., 72, 1765-1782, https://doi.org/10.1175/JAS-D-14-0318.1.

- — , and L. D. Grasso, 2004: A new look at the problem of tropical cyclones in vertical shear flow: Vortex resiliency. J. Atmos. Sci., 61, 3-22, https://doi.org/10.1175/1520-0469(2004) 061<0003:ANLATP $>2.0 . \mathrm{CO} ; 2$. 
_ R. Rogers, and S. Lorsolo, 2013: Environmental flow impacts on tropical cyclone structure diagnosed from airborne Doppler radar composites. Mon. Wea. Rev., 141, 2949-2969, https:// doi.org/10.1175/MWR-D-12-00334.1.

Riemer, M., and M. T. Montgomery, 2011: Simple kinematic models for the environmental interaction of tropical cyclones in vertical wind shear. Atmos. Chem. Phys., 11, 9395-9414, https://doi.org/10.5194/acp-11-9395-2011.

_- and F. Laliberté, 2015: Secondary circulation of tropical cyclones in vertical wind shear: Lagrangian diagnostic and pathways of environmental interaction. J. Atmos. Sci., 72, 3517-3536, https://doi.org/10.1175/JAS-D-14-0350.1.

- M. T. Montgomery, and M. E. Nicholls, 2010: A new paradigm for intensity modification of tropical cyclones: Thermodynamic impact of vertical wind shear on the inflow layer. Atmos. Chem. Phys., 10, 3163-3188, https://doi.org/10.5194/ acp-10-3163-2010.

Rios-Berrios, R., and R. D. Torn, 2017: Climatological analysis of tropical cyclone intensity changes under moderate vertical wind shear. Mon. Wea. Rev., 145, 1717-1738, https://doi.org/ 10.1175/MWR-D-16-0350.1.

,$- \ldots$, and C. A. Davis, 2016a: An ensemble approach to investigate tropical cyclone intensification in sheared environments. Part I: Katia (2011). J. Atmos. Sci., 73, 71-93, https:// doi.org/10.1175/JAS-D-15-0052.1.

$\longrightarrow,-$, and $—, 2016 \mathrm{~b}$ : An ensemble approach to investigate tropical cyclone intensification in sheared environments. Part II: Ophelia (2011). J. Atmos. Sci., 73, 1555-1575, https:// doi.org/10.1175/JAS-D-15-0245.1.

Ritchie, E. A., and G. J. Holland, 1993: On the interaction of tropical-cyclone-scale vortices. II: Discrete vortex patches. Quart. J. Roy. Meteor. Soc., 119, 1363-1379, https://doi.org/ 10.1002/qj.49711951407.

Rogers, R., 2010: Convective-scale structure and evolution during a high-resolution simulation of tropical cyclone rapid intensification. J. Atmos. Sci., 67, 44-70, https://doi.org/10.1175/ 2009JAS3122.1.

__ , P. D. Reasor, and J. A. Zhang, 2015: Multiscale structure and evolution of Hurricane Earl (2010) during rapid intensification. Mon. Wea. Rev., 143, 536-562, https://doi.org/ 10.1175/MWR-D-14-00175.1.

—, J. A. Zhang, J. Zawislak, H. Jiang, G. R. Alvey III, E. J. Zipser, and S. N. Stevenson, 2016: Observations of the structure and evolution of Hurricane Edouard (2014) during intensity change. Part II: Kinematic structure and the distribution of deep convection. Mon. Wea. Rev., 144, 3355-3376, https://doi.org/ 10.1175/MWR-D-16-0017.1.

— , P. D. Reasor, and J. A. Zhang, 2017: Reply to "Comments on 'Multiscale structure and evolution of Hurricane Earl (2010) during rapid intensification."' Mon. Wea. Rev., 145, 15731575, https://doi.org/10.1175/MWR-D-16-0414.1.

Ryglicki, D. R., and R. E. Hart, 2015: An investigation of centerfinding techniques for tropical cyclones in mesoscale models. J. Appl. Meteor. Climatol., 54, 825-846, https://doi.org/10.1175/ JAMC-D-14-0106.1.

Schecter, D. A., 2016: Development and nondevelopment of binary mesoscale vortices into tropical cyclones in idealized numerical experiments. J. Atmos. Sci., 73, 1223-1254, https:// doi.org/10.1175/JAS-D-15-0028.1.

2017: A computational study on the nature of meso- $\beta$ scale vortex coalescence in a tropical atmosphere. $J . A d v$. Model. Earth Syst., 9, 1366-1398, https://doi.org/10.1002/ 2016MS000777.
Simpson, J., E. Ritchie, G. J. Holland, J. Halverson, and S. Stewart, 1997: Mesoscale interactions in tropical cyclone genesis. Mon. Wea. Rev., 125, 2643-2661, https://doi.org/10.1175/1520-0493(1997) 125<2643:MIITCG > 2.0.CO;2.

Skamarock, W. C., and Coauthors, 2008: A description of the Advanced Research WRF version 3. NCAR Tech. Note NCAR/TN-475+STR, 113 pp., https://doi.org/10.5065/ D68S4MVH.

Smith, R. K., M. T. Montgomery, and H. Zhu, 2005: Buoyancy in tropical cyclones and other rapidly rotating atmospheric vortices. Dyn. Atmos. Oceans, 40, 189-208, https://doi.org/ 10.1016/j.dynatmoce.2005.03.003.

__ J. A. Zhang, and M. T. Montgomery, 2017: The dynamics of intensification in a hurricane Weather Research and Forecasting simulation of Hurricane Earl (2010). Quart. J. Roy. Meteor. Soc., 143, 293-308, https://doi.org/10.1002/ qj. 2922.

Stevenson, S. N., K. L. Corbosiero, and J. Molinari, 2014: The convective evolution and rapid intensification of Hurricane Earl (2010). Mon. Wea. Rev., 142, 4364-4380, https://doi.org/ 10.1175/MWR-D-14-00078.1.

Sumwalt, R. L., III, C. A. Hart, E. F. Weener, and T. B. DinhZahr, 2017: Safety recommendation report: Tropical cyclone information for mariners. National Transportation Safety Board Tech. Rep. MSR-17/02, 21 pp., https://www.ntsb. gov/investigations/AccidentReports/Reports/MSR1702.pdf.

Tang, B., and K. Emanuel, 2012: Sensitivity of tropical cyclone intensity to ventilation in an axisymmetric model. J. Atmos. Sci., 69, 2394-2413, https://doi.org/10.1175/JAS-D11-0232.1.

—, R. Rios-Berrios, J. J. Alland, J. D. Berman, and K. L. Corbosiero, 2016: Sensitivity of axisymmetric tropical cyclone spinup time to dry air aloft. J. Atmos. Sci., 73, 4269-4287, https://doi.org/10.1175/JAS-D-16-0068.1.

Tao, C., and H. Jiang, 2015: Distributions of shallow to very deep precipitation-convection in rapidly intensifying tropical cyclones. J. Climate, 28, 8791-8824, https://doi.org/10.1175/ JCLI-D-14-00448.1.

—_ _ - and J. Zawislak, 2017: The relative importance of stratiform and convective rainfall in rapidly intensifying tropical cyclones. Mon. Wea. Rev., 145, 795-809, https:// doi.org/10.1175/MWR-D-16-0316.1.

Tao, D., and F. Zhang, 2014: Effect of environmental shear, seasurface temperature, and ambient moisture on the formation and predictability of tropical cyclones: An ensemble-mean perspective. J. Adv. Model. Earth Syst., 6, 384-404, https:// doi.org/10.1002/2014MS000314.

— , and — 2015: Effects of vertical wind shear on the predictability of tropical cyclones: Practical versus intrinsic limit. J. Adv. Model. Earth Syst., 7, 1534-1553, https://doi.org/ 10.1002/2015MS000474.

Van Sang, N., R. K. Smith, and M. T. Montgomery, 2008: Tropicalcyclone intensification and predictability in three dimensions. Quart. J. Roy. Meteor. Soc., 134, 563-582, https://doi.org/ 10.1002/qj.235.

Wadler, J. B., R. F. Rogers, and P. D. Reasor, 2018: The relationship between spatial variations in the structure of convective bursts and tropical cyclone intensification as determined by airborne Doppler radar. Mon. Wea. Rev., 146, 761-780, https://doi.org/10.1175/MWR-D-17-0213.1.

Yuter, S. E., and R. A. Houze Jr., 1995: Three-dimensional kinematic and microphysical evolution of Florida cumulonimbus. Part II: Frequency distributions of vertical velocity, reflectivity, and 
differential reflectivity. Mon. Wea. Rev., 123, 1941-1963, https:// doi.org/10.1175/1520-0493(1995)123<1941:TDKAME > 2.0.CO;2.

Zagrodnik, J. P., and H. Jiang, 2014: Rainfall, convection, and latent heating distributions in rapidly intensifying tropical cyclones. J. Atmos. Sci., 71, 2789-2809, https://doi.org/10.1175/ JAS-D-13-0314.1.

Zawislak, J., H. Jiang, G. R. Alvey III, E. J. Zipser, R. F. Rogers, J. A. Zhang, and S. N. Stevenson, 2016: Observations of the structure and evolution of Hurricane Edouard (2014) during intensity change. Part I: Relationship between the thermodynamic structure and precipitation. Mon. Wea. Rev., 144, 3333-3354, https://doi.org/10.1175/MWR-D-160018.1.

Zhang, F., and D. Tao, 2013: Effects of vertical wind shear on the predictability of tropical cyclones. J. Atmos. Sci., 70, 975-983, https://doi.org/10.1175/JAS-D-12-0133.1. 